\title{
Technical Report 1185
}

\section{Personality Profiles of Experienced U.S. Army Aviators Across Mission Platforms}

\section{Robert Grice}

Liberty University

Consortium Research Fellows Program

Lawrence C. Katz

U.S. Army Research Institute

September 2006

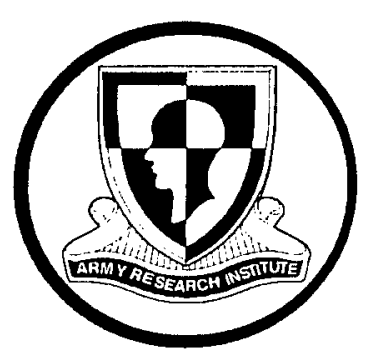

United States Army Research Institute for the Behavioral and Social Sciences 


\section{U.S. Army Research Institute for the Behavioral and Social Sciences}

\section{A Directorate of the Department of the Army Deputy Chief of Staff, G1}

\section{Authorized and approved for distribution:}

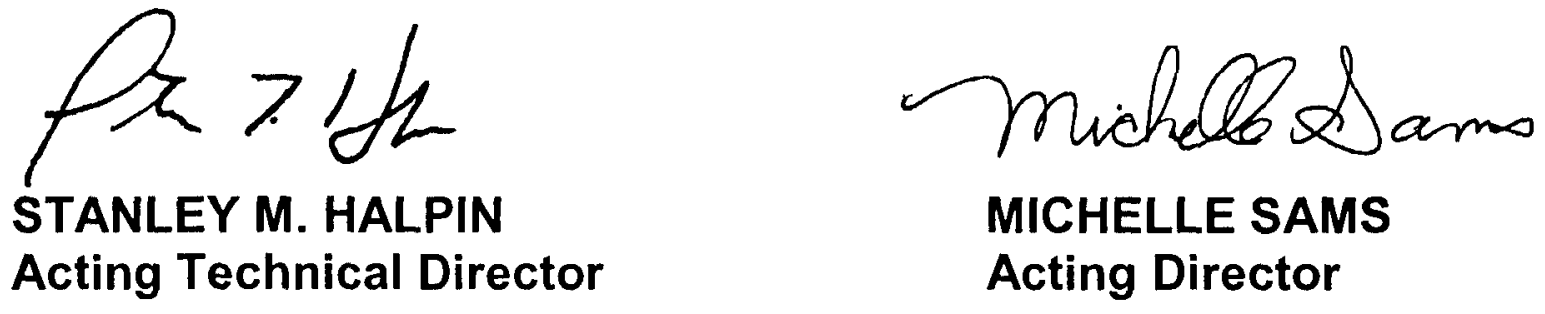

Technical review by

David M. Johnson, U.S. Army Research Institute

Michelle L. Zbylut, U.S. Army Research Institute

\section{NOTICES}

DISTRIBUTION: Primary distribution of this Technical Report has been made by ARI. Please address correspondence concerning distribution of reports to: U.S. Army Research Institute for the Behavioral and Social Sciences, Attn: DAPC-ARI-MS, 2511 Jefferson Davis Highway, Arlington, Virginia 22202-3926.

FINAL DISPOSITION: This Technical Report may be destroyed when it is no longer needed. Please do not return it to the U.S. Army Research Institute for the Behavioral and Social Sciences.

NOTE: The findings in this Technical Report are not to be construed as an official Department of the Army position, unless so designated by other authorized documents. 


\begin{tabular}{|c|c|c|c|c|c|}
\hline \multicolumn{6}{|c|}{ REPORT DOCUMENTATION PAGE } \\
\hline \multicolumn{2}{|c|}{$\begin{array}{l}\text { 1. REPORT DATE (dd-mm-yy) } \\
\text { September } 2006\end{array}$} & \multicolumn{2}{|c|}{$\begin{array}{l}\text { 2. REPORT TYPE } \\
\text { Final }\end{array}$} & \multicolumn{2}{|c|}{$\begin{array}{l}\text { 3. DATES COVERED (from... to } \\
\text { June } 2005 \text {-July } 2006\end{array}$} \\
\hline \multirow{2}{*}{\multicolumn{4}{|c|}{$\begin{array}{l}\text { 4. Title And Subtitle } \\
\text { Personality Profiles Of Experienced U.S. Army Aviators } \\
\text { Across Mission Platforms }\end{array}$}} & \multicolumn{2}{|c|}{ 5a. CONTRACT OR GRANT NUMBER } \\
\hline & & & & \multicolumn{2}{|c|}{$\begin{array}{l}\text { 5b. PROGRAM ELEMENT NUMBER } \\
633007\end{array}$} \\
\hline \multirow{3}{*}{\multicolumn{4}{|c|}{$\begin{array}{l}\text { 6. AUTHOR(S) } \\
\text { Robert Grice (Liberty University) and } \\
\text { Lawrence C. Katz (U.S. Army Research Institute) }\end{array}$}} & \multicolumn{2}{|c|}{$\begin{array}{l}\text { 5c. PROJECT NUMBER } \\
\text { A792 }\end{array}$} \\
\hline & & & & \multicolumn{2}{|c|}{$\begin{array}{l}\text { 5d. TASK NUMBER } \\
308\end{array}$} \\
\hline & & & & \multicolumn{2}{|c|}{ 5e. WORK UNIT NUMBER } \\
\hline \multicolumn{4}{|c|}{$\begin{array}{l}\text { 7. PERFORMING ORGANIZATION NAME(S) AND ADDRESS(ES) } \\
\text { U.S. Army Research Institute for the Behavioral and Social } \\
\text { Sciences } \\
\text { ATTN: DAPE-ARI-IR } \\
\text { Bldg } 5100 \\
\text { Ft. Rucker, AL } 36362-5354\end{array}$} & \multicolumn{2}{|c|}{ 8. PERFORMING ORGANIZATION REPORT NUMBER } \\
\hline \multirow{2}{*}{\multicolumn{4}{|c|}{$\begin{array}{l}\text { 9. SPONSORING/MONITORING AGENCY NAME(S)AND ADDRESS(ES) } \\
\text { U.S. Army Research Institute for the Behavioral \& Social Sciences } \\
\text { ATTN: DAPE-ARI-IR, (RWARU) } \\
2511 \text { Jefferson Davis Highway } \\
\text { Arlington, VA 22202-3926 }\end{array}$}} & \multicolumn{2}{|c|}{$\begin{array}{l}\text { 10. MONITOR ACRONYM } \\
\text { ARI-RWARU }\end{array}$} \\
\hline & & & & \multicolumn{2}{|c|}{$\begin{array}{l}\text { 11. MONITOR REPORT NUMBER } \\
\text { Technical Report } 1185\end{array}$} \\
\hline \multicolumn{6}{|c|}{$\begin{array}{l}\text { 12. DISTRIBUTION/AVAILABILITY STATEMENT } \\
\text { Approved for public release; distribution is unlimited. }\end{array}$} \\
\hline \multicolumn{6}{|c|}{ Subject Matter POC: Robert Grice } \\
\hline \multicolumn{6}{|c|}{$\begin{array}{l}\text { 14. ABSTRACT (Maximum 200 words): } \\
\text { To address the selection-related question, "What does the personality profile of the Army aviator of today look like?" } \\
75 \text { experienced Army aviators attending advanced leadership training completed the Revised NEO Personality } \\
\text { Inventory, with scores depicting the five personality factors of: neuroticism, extraversion, openness, agreeableness, } \\
\text { and conscientiousness. To address the classification-related question, "Are there certain personality profiles that } \\
\text { distinguish among attack, scout, cargo, and utility pilots?" factor scores and their subsumed facet scores were } \\
\text { compared across respondents representing the four mission platforms. Overall sample profiles and score differences } \\
\text { among platforms are presented. }\end{array}$} \\
\hline \multicolumn{6}{|c|}{$\begin{array}{l}\text { 15. SUBJECT TERMS } \\
\text { Aviator personality; Army aviator; personality; neuroticism; extraversion; openness; agreeableness; } \\
\text { conscientiousness; NEO-PI-R }\end{array}$} \\
\hline \multicolumn{3}{|c|}{ SECURITY CLASSIFICATION OF } & 19. LIMITATION OF & \multirow{2}{*}{$\begin{array}{l}\text { 20. NUMBER } \\
\text { OF PAGES } \\
46\end{array}$} & 21. RESPONSIBLE PERSON \\
\hline $\begin{array}{l}\text { 16. REPORT } \\
\text { Unclassified }\end{array}$ & $\begin{array}{l}\text { 17. ABSTRACT } \\
\text { Unclassified }\end{array}$ & $\begin{array}{l}\text { 18. THIS PAGE } \\
\text { Unclassified }\end{array}$ & $\begin{array}{l}\text { ABSTRACT } \\
\text { Unlimited }\end{array}$ & & $\begin{array}{l}\text { Ellen Kinzer } \\
\text { Technical Publication Specialist } \\
(703) 602-8047\end{array}$ \\
\hline
\end{tabular}


Technical Report 1185

\title{
Personality Profiles of Experienced U.S. Army Aviators Across Mission Platforms
}

\author{
Robert Grice \\ Liberty University \\ Consortium Research Fellows Program \\ Lawrence C. Katz \\ U.S. Army Research Institute
}
Rotary-Wing Aviation Research Unit
William R. Howse, Chief

U.S. Army Research Institute for the Behavioral and Social Sciences 2511 Jefferson Davis Highway, Arlington, VA 22202-3926

September 2006

Army Project Number 633007A792
Personnel Performance and Training

Approved for public release; distribution is unlimited 


\section{PERSONALITY PROFILES OF EXPERIENCED U.S. ARMY AVIATORS ACROSS MISSION PLATFORMS}

\section{EXECUTIVE SUMMARY}

Research Requirement:

In June 2004, the U.S. Army Research Institute for the Behavioral and Social Sciences (ARI) was tasked with conducting the research and development towards a new Selection Instrument for Flight Training (SIFT). The Army's stated objective was to develop a computerbased and web-administered selection instrument for Army flight training with emphasis upon aptitudes for Future Force aviator performance. To determine what those aptitudes might be, a review of the selection literature and an aviator job analysis were conducted, and they indicated that personality is an attribute that might warrant consideration in Army aviator selection and aircraft assignment. Thus, the goals of this investigation were to identify those personality traits for which one may wish to select, and to determine which personality factors might be useful in classification.

\section{Procedure:}

To address the selection-related question, "What does the personality profile of the Army aviator of today look like?" 75 experienced Army aviators attending advanced leadership training completed the Revised NEO Personality Inventory (NEO-PI-R). The NEO-PI-R is a 240-item self-report questionnaire in which subjects rate statements on a scale of 0 (strongly disagree) to 4 (strongly agree) and scores depict the five personality factors of: Neuroticism, Extraversion, Openness, Agreeableness, and Conscientiousness.

To address the classification-related question, "Are there certain personality profiles that distinguish among attack, scout, cargo, and utility pilots?" factor scores and their subsumed facet scores were compared across respondents representing the four mission platforms.

Findings:

Regarding the overall personality profiles of aviators, the total sample scored low to average across the five factors. Aviators in this sample were in the low range on the Neuroticism and the Openness scales, suggesting that these respondents are able to mitigate the influence of stress in the cockpit and prefer to obey standing operating procedures rather than engage in efforts to create novel approaches to cockpit decision-making.

Attack pilots scored lower than the others on the Agreeableness scale. Follow-up analysis of the Agreeableness factor scores revealed significant differences between the attack and the utility pilots, but not between attack and scout or cargo aviators. The source of difference in Agreeableness was in the facet of Trust, with attack aviators scoring lowest among the four mission platforms on this facet. 
Utilization and Dissemination of Findings:

The results of this work were briefed to COL (now BG) William Wolf, Deputy Commanding General, U.S. Army Aviation Warfighting Center, on 6 July 2006. This product is one of many emanating from the SIFT effort. The contents of this report document the personality evaluation portion of the effort, which contributes to the development of a classification instrument as a follow-on to the SIFT selection instrument. Documentation of the development of this classification instrument is necessary to establish the scientific and theoretical underpinnings of the test as well as to provide a detailed base from which revisions can be made. 
INTRODUCTION ............................................................... 1

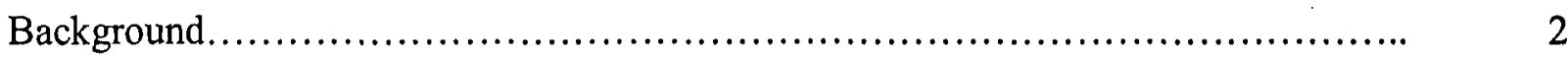

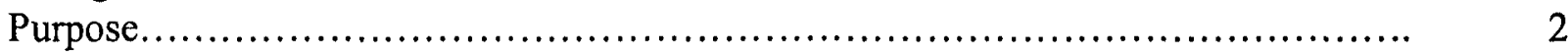

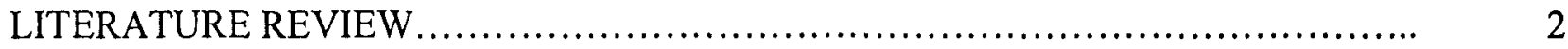

The Aviator Personality ........................................................ 3

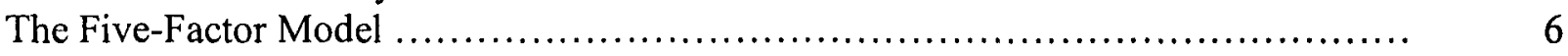

Personality and Performance................................................... 9

Rationale for Using the FFM in this Investigation .............................. 14

RESEARCH QUESTIONS................................................. 15

RESEARCH DESIGN ......................................................... 16

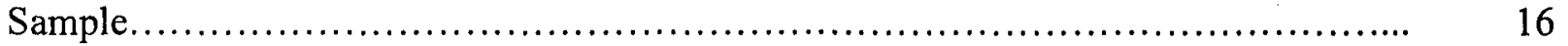

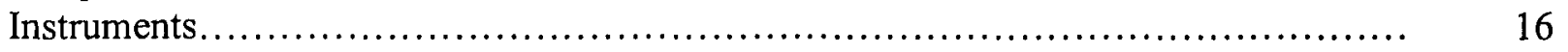

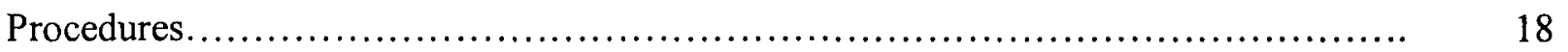

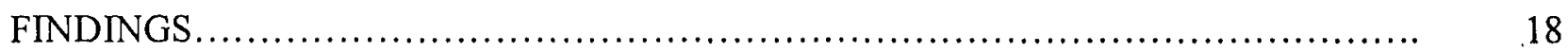

Demographics.................................................................. 18

Research Question \#1 ............................................................. 19

Research Question \#2 ........................................................ 21

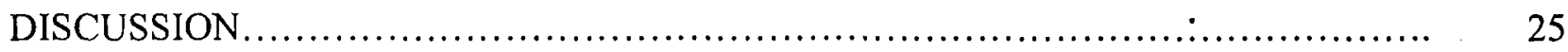

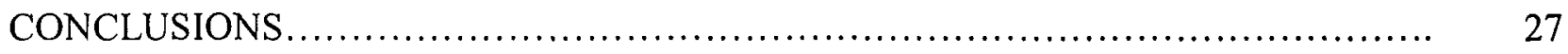

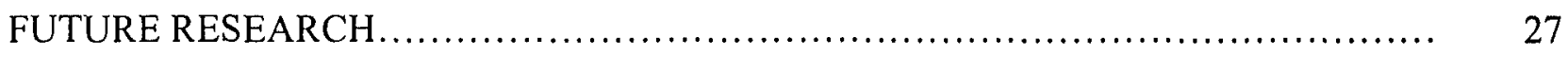

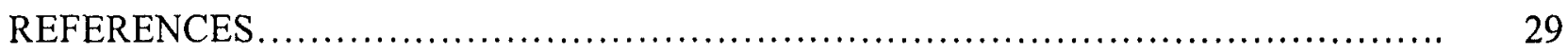

\section{LIST OF TABLES}

TABLE 1. FACTOR DESCRIPTIONS OF THE FIVE-FACTOR MODEL $\ldots \ldots \ldots \ldots \ldots \ldots .7$

TABLE 2. THE FACETS OF THE FIVE-FACTOR MODEL ............................. 7

TABLE 3. DESCRIPTIVE STATISTICS OF TOTAL SAMPLE NEO-PI-R FACTOR SCORES... 
TABLE 4. COMPARISON OF TOTAL SAMPLE AND MISSION PLATFORM

TABLE 5. RANKING OF FACTOR SCORES ACROSS MISSION PLATFORMS....... 20

TABLE 6. MULTIVARIATE ANALYSIS OF PLATFORM AND PERSONALITY DOMAINS

TABLE 7. ANALYSIS OF VARIANCE FOR THE FIVE-FACTOR MODEL FACTORS.

TABLE 8. PAIRWISE COMPARISONS AMONG MISSION PLATFORMS

TABLE 9. PAIRWISE COMPARISONS OF TRUST AMONG MISSION PLATFORMS 


\section{PERSONALITY PROFILES OF EXPERIENCED U.S. ARMY AVIATORS ACROSS MISSION PLATFORMS}

Introduction

The selection test for Army flight school is the Alternate Flight Aptitude Selection Test (AFAST), which has been in service since 1988. In June 2004, the U. S. Army Research Institute for the Behavioral and Social Sciences (ARI) was tasked with conducting the research and development towards a new Selection Instrument for Flight Training (SIFT) to correct or minimize risks associated with several deficiencies identified in the AFAST. The Army's stated objective was to develop a computer-based, web-administered selection instrument for Army flight training with emphasis upon aptitudes for Future Force aviator performance. To uncover what those aptitudes might be, the first task was to review the relevant selection literature in order to collect information that could be used to produce a rational recommendation for a specific selection and testing strategy for Army aviation. Concurrently, a job analysis was conducted in which the activities performed by U. S. Army aviators were analyzed and the personal attributes required to perform those activities were examined. Based on the results of the job analysis and the literature review, measurements of the following attributes were recommended for inclusion in a prototype battery for validity testing: Cognitive Ability, Perceptual Speed \& Accuracy, Motivation/Attitude, Task Prioritization, and Personality or Temperament.

It is not surprising that personality emerged as an important attribute to measure in attempting to predict performance in flight school. Military aviators are frequently depicted in movies as demonstrating personality traits that distinguish them from the general public. Specifically, they are often presented as being extraverted, risk-taking, mavericks, with little interest in procedural compliance. Research has supported the assumption that military aviators often exhibit personality trait levels that distinguish them from the general public (Callister, King, Retzlaff, \& Marsh, 1997; 1999; Fitzgibbons, Davis, \& Schutte, 2004; Helton \& Street, 1993; Street \& Helton, 1993). Further, aviation research has supported the notion that personality trait levels can predict cockpit performance (e.g., mission success, teamwork, risktaking), especially during flight training (Anesgart \& Callister, 2001).

In addition to SIFT, the Army requested that ARI develop and validate a classification instrument for tracking selected aviators into an aircraft type, corresponding to a specific mission platform. Following a Common Core flight training program, student aviators are assigned to one of four advanced tracks for operational aircraft-specific training: Scout, Attack, Cargo, or Utility. Currently, operational aircraft classification decisions are based on order-of-merit rankings, and determined by the needs of the Army. A classification instrument that provides predictive validity for matching individuals with the aircraft and mission types in which they are most likely to succeed would potentially increase the satisfaction levels and retention of aviators. Personality is a factor that might warrant consideration as one of the attributes to be evaluated in this initial aircraft assignment. 


\section{Background}

The roles, or mission platforms, of U.S. Army rotary-wing aircraft include: attack, reconnaissance (scout/observation), and transportation (utility or cargo). Aircraft are specifically designed and built to perform these missions. For instance, attack aircraft, including the AH64A, Apache, and AH-64D, Apache Longbow, are primarily designed for offensive combat missions. They typically provide air artillery support for ground troops using air-to-ground missiles. Scout/Observation aircraft, such as the OH-58D, Kiowa, provide reconnaissance, or information-gathering, functions in the combat environment. These aircraft are small and are designed to be not easily detected by the enemy. Utility aircraft, such as the UH-60A, Blackhawk, provide transportation of light-weight supplies and small groups of personnel in a combat support role. Cargo aircraft, such as the CH-47D, Chinook, are larger aircraft capable of moving heavy supplies or transporting larger groups of personnel.

Immediately following Common Core aviation instruction, student aviators receive specialized training in order to be qualified to fly a specific aircraft, and the cost of training rotary-wing aviators is considerable. For instance, each year there are approximately 1,200 new aviators trained at Fort Rucker, Alabama at a cost of approximately $\$ 225,000$ per student (Colucci, 2002). Consequently, Army aviation has an interest in reducing attrition by identifying factors that might contribute to aviators perceiving a greater sense of congruence between their individual characteristics and the task demands related to their assigned aircraft. Individual characteristics include personality traits, especially when traits are construed as including interests, dispositions, and preferences (Barrick, Mount, \& Gupta, 2003). Intano, Howse, and Lofaro (1991) suggested that matching individual traits with the task demands of each mission platform might indicate "the aircraft for which the [aviation] candidate might be expected to have the highest probability of successfully completing flight training and of having a successful flight career" (p. 15).

\section{Purpose}

Army aviation's dual focus on selection and classification precipitated two separate but related objectives for the current study. To be useful as a selection attribute, personality would have to be shown to distinguish the U.S. Army rotary-wing aviator from the general population. In other words, one must answer the question, "What does the personality profile of the Army aviator of today look like?" in order to identify those personality traits for which one may wish to select. To serve a classification role, personality would have to be shown to distinguish among experienced aviators in each of the four mission types. That is, "Are there certain personality profiles that typify the attack pilot versus a scout, cargo, or utility pilot?"

\section{Literature Review}

Four on-line research databases were searched for this investigation. These included PsychInfo, EBSCOhost, Annual Review of Psychology, and the Defense Technical Information Center (DTIC). The databases were searched using terms such as "aviator personality," "personality and performance," and "aviator performance." DTIC is devoted primarily to military technical reports while the remaining databases report primarily refereed journal articles. 
This section presents the findings of the literature review. First, the research exploring the notion of an "aviator personality" will be presented. Then the Five-Factor Model (FFM; Costa \& McCrae, 1985) will be described and discussed, with focused attention on research linking the FFM with workplace performance and with "person-environment fit" models. Research will be presented that links personality to performance in general and more specifically to military performance. Finally, a rationale will be provided for using an FFM-based instrument for measuring personality with experienced U.S. Army rotary-wing aviators in the current investigation.

\section{The Aviator Personality}

Attempts to describe the personalities of aviators date to the early days of aviation (Dockery \& Isaacs 1921; Rippon \& Manuel, 1918). Even then the subject of aviator personality was confusing as illustrated in the anecdotal descriptions offered by Rippon and Manuel that aviators are "outgoing" and "risk-taking" while Dockery and Issacs described aviators as "methodical" and "quiet." The evolution of trait personality theory and the development of related personality instruments allowed for a more reliable means to identify the personality traits of this unique population.

While studies have found that aviators often report trait levels that distinguish them from the general public (Fitzgibbons et al., 2004), caution should be exercised in attempting to generalize one personality profile to all aviators (Retzlaff \& Gibertini, 1987). A common finding is that aviators seem to group around certain clusters of personality traits (Kanki \& Palmer, 1993; Retzlaff \& Gibertini). The conclusion has been that these clusters of traits can predict which aviators are likely to have the "right stuff" or the "wrong stuff" in terms of performance (Picano, 1991; Retzlaff \& Gibertini).

Kanki and Palmer (1993) reported that three major personality groups emerged from their review of flightcrew composition research. First, positive instrumental skill/expressive aviators are highly motivated and goal-oriented and they are concerned about the interpersonal dynamics that can influence crew performance. Second, negative instrumental aviators demonstrate a high motivation for goal achievement but have little regard for developing interpersonal skills or relationships with crewmembers. Third, negative expressive aviators reported a lower motivation towards achieving goals and little concern for enhancing interpersonal relationships with other crewmembers.

The influence of these personality types on crew performance was evident in research findings. The positive instrumental skill/expressive aviators were found to consistently lead high performing crews in simulation performance and observer scores (Kanki \& Palmer, 1993). Kanki, Palmer, and Veinott (1991) studied aircrews by comparing personality and cockpit communication. They found that negative expressive captains communicated less and led aircrews that made the most errors. Aircrews led by positive instrumental/expressive captains reported the highest frequency of communication between crewmembers and demonstrated the highest performance. The negative instrumental captains received more commands from their first officer which indicated that they might have invited more authoritarian behaviors from other crewmembers. 
The personality cluster findings of Retzlaff and Gibertini (1987) have become a common categorization of aviator personality traits in other studies. They administered the Personality Research Form and the Millon Clinical Multiaxial Inventory (MCMI; Millon, 1977) to 350 male students entering U.S. Air Force (USAF) Undergraduate Pilot Training. Rather than finding one personality profile that could be generalized to all of the aviators, they found that the trait levels reported by these aviators produced three clusters of traits they labeled "wrong stuff," "companyman," and "right stuff" in terms of characteristics they perceived as being most conducive to performance as aviators.

Retzlaff and Gibertini (1987) offered a description of each group of aviators. The "wrong stuff" aviators comprised $21 \%$ of their sample and were described as being cautious, conforming, polite, compulsive, and retiring and they were lowest in achievement motivation. These aviators were likely to be attrited from military aviation or perform at minimal levels because their preference for the perceived vocational stability and security of military life exceeded their desire to fly.

The "company-man" group comprised $58 \%$ of the sample and was described as being inclined to dominance, endurance, achievement, order, and affiliation. The "company-man" aviators often share an equal concern about their performance in the cockpit and about maintaining a positive public image that is favorable to their employer. These aviators were "bythe-book" and preferred "a matter-of-fact, highly structured approach to need-gratification and coping skills" (Retzlaff \& Gibertini, 1987, p. 397). This group is composed of stable, pragmatic, compliant aviators who value the comradeship of peers. These aviators would likely demonstrate professionalism and competence in the cockpit and would likely prefer noncombative aircraft.

The "right stuff" group was determined based upon the consistency between their traits and traits commonly used to stereotype military aviators. The "right stuff" group comprised $21 \%$ of the sample and was described as (a) aggressive, (b) dominant, (c) exhibitionistic, (d) impulsive, and (e) playful. They appeared as "self-possessed to the point of arrogance, dramatic, excitable, easily bored with routine tasks, and at times erratic and impulsive" (Retzlaff \& Gibertini, 1987, p. 397). These aviators would likely be more committed to the mission and be more open to risk than aviators in the other clusters.

The "three groups" findings of Retzlaff and Gibertini (1987) have been adopted in other research with aviators with some modification. For instance, "company-man" was changed to "no stuff" (Gregorich, Helmreich, Wilhelm, \& Chidester, 1989). The same descriptive categories of traits were supported in a study with successful applicants undergoing astronaut training (Musson, Sandal, \& Helmreich, 2004). Though not empirically linked, similarities exist between Musson et al.'s three categories of traits and the FFM. For instance, Callister et al. (1997) found that male and female USAF student aviators reported high Extraversion scores, which they interpreted to be traits similar to Retzlaff and Gibertini's "right stuff" such as aggressive, exhibitionistic, and dominant. The same student aviators scored low in Agreeableness. Characteristics associated with high Agreeableness would be similar to those identified as representing the "wrong stuff" such as being too conforming and polite. 
The development of personality instruments that measured trait levels introduced the possibility of being able to go a step beyond subjective opinions in describing aviators. The Minnesota Multiphasic Personality Inventory (MMPI; Hathaway \& McKinley, 1943) was one of the first empirically validated personality instruments to be widely used. The MMPI was later revised resulting in the MMPI - 2 (Butcher, Dalstrom, Graham, Tellegen, \& Kaemmer, 1989). The MMPI, MMPI-2, and the MCMI enabled the measurement of traits so findings could be validated by subsequent research. For example, research using instruments such as versions of the MMPI or the MCMI have resulted in descriptions of aviators as being "self-assertive," and "action oriented," with "high achievement needs," and "stable self-identity" (Hormann \& Maschke, 1996; Shinar, 1995).

Despite the advantages of incorporating aviator personality traits into selection, aircraft placement, and training, confusion still remains over what traits constitute an aviator's personality profile. Different personality instruments have yielded results that can be confusing or difficult to interpret in relation to job performance, especially since these instruments were designed for a clinical population with psychopathology (Dolgin, Kay, Langelier, Wasel, \& Hoffman, 2002; King, McGlohn, \& Retzlaff, 1997; Retzlaff \& Gibertini, 1987). Findings using the MMPI, for example, have proposed that aviators were social, hysteric, aggressive, selfconfident, and intellectually-striving (e.g., Culpepper, Jennings, \& Perry, 1972).

Findings with other personality instruments have lacked clarity in describing aviator personality profiles. For instance, studies using the Edwards Personal Preference Schedule (Edwards, 1959) found aviators to be more achievement-oriented, dominant, and aggressive while reporting less nurturance, affiliation, and abasement than their non-aviation peers (Ashman \& Telfer, 1983; Reinhardt, 1970). Other studies using the Eysenck Personality Inventory (Eysenck, 1970) found successful aviators were introverts, dependable, practical, and pragmatic (Bucky \& Ridley, 1972; Jessup \& Jessup, 1971).

The confusion over describing aviator personality profiles appears to have been reduced with creation of the Revised NEO Personality Inventory (NEO-PI-R; Costa \& McCrae, 1992). The NEO-PI-R has been used to identify distinctive personality traits for aviators in comparison with the general public and between genders. For example, McGlohn (1996) administered the NEO-PI-R to a sample of USAF mid-career aviators to see if scores varied between male and female aviators and between female aviators and female college students. Findings indicated that male aviators scored lowest and college females scored highest on Neuroticism.

Extraversion scores were similar across groups and were in the high range. Female aviators and college females scored in the high range and male aviators scored in the average range on Openness. All scores on Agreeableness were in the average range with male aviators scoring lowest and college females scoring the highest. College females scored lowest and in the low range on Conscientiousness while both groups of aviators scored in the average range. Male aviators scored the highest on Conscientiousness.

Fitzgibbons et al. (2004) surveyed 93 commercial aviators using the NEO-PI-R. Results indicated that the majority of these aviators scored low on Neuroticism. Forty-two percent scored high on Extraversion. Thirty-seven percent of the aviators scored low on Openness. 
Over half (58\%) scored high or very high on Conscientiousness. Fitzgibbons and associates generated a personality profile based on their findings suggesting that aviators in their study were emotionally stable and highly conscientious about their performance. These aviators were likely to be trusting, straightforward, and assertive. Fitzgibbons et al. noted that their findings were consistent with the personality profiles offered in other studies with aviators (Hormann \& Maschke, 1996; Picano, 1991). Fitzgibbons and associates concluded by commenting, "This finding could indicate that there is a universal pilot personality, irrespective of experience or position" (p. 5).

Callister et al. (1997) used the NEO-PI-R to identify the personality profiles of 1301 USAF student pilots. They found the average male student pilot was more extraverted and less agreeable than men in the general public. "He is more assertive, active, and excitement-seeking, and describes himself as more competent and achievement striving and less vulnerable than men in the general population" (p. 5). Female student pilots were found to be more extraverted and less agreeable than women in the general public. They reported being more open to emotions, new ideas, and creative thoughts. Females were similar to the male student pilots in that they were more active, achievement striving, and assertive, but less socially compliant than females in the general public.

\section{The Five-Factor Model}

The NEO-PI-R is based upon the Five-Factor Model taxonomy of personality. The FFM, also identified as the "Big Five," has become one of the most popular methodologies for connecting personality traits with workplace performance (e.g., Barrick \& Mount, 1991; Barrick, Mount, \& Judge, 2001; Digman, 1989, 1990; Mount, Barrick, \& Stewart, 1998; Tett \& Burnett, 2003; Waldman, Atwater, \& Davidson, 2004). The FFM grew out of factor analyses of personality attributes rather than a specific theory (Fiske, 1949; Norman, 1963; Tupes, 1957; Tupes \& Christal, 1961).

Though the labels for the five factors of personality have changed over the years, Costa and McCrae (1985) provided the factor labels for the FFM that are measured by the NEO-PI-R. The FFM is based upon five global factorial domains of personality: Neuroticism, Extraversion, Openness, Agreeableness, and Conscientiousness (Table 1).

The NEO-PI-R is the most comprehensive instrument that measures the facets and factors of the FFM. The NEO-PI-R is a self-report instrument that consists of 240 items. Raw scores are tallied and result in thirty facet scores. The facet scores are grouped under the five global domains or factors of the FFM. The sum of group facet scores produces the factor scores for each group. 
Table 1

Factor Descriptions of the Five-Factor Model

\begin{tabular}{|l|l|}
\hline Factor & Description \\
\hline Neuroticism & $\begin{array}{l}\text { Contrasts emotional adjustment and stability with maladjustment such as } \\
\text { a frequent depression or anxiety }\end{array}$ \\
\hline Extraversion & $\begin{array}{l}\text { Contrasts aspects of sociability with a disposition towards introversion } \\
\text { and independence }\end{array}$ \\
\hline Openness & $\begin{array}{l}\text { Contrasts aspects of imagination and curiosity with conventionality and } \\
\text { obeying the rules }\end{array}$ \\
\hline Agreeableness & $\begin{array}{l}\text { Contrasts aspects of altruism and compliance with aspects of antagonism } \\
\text { and egocentrism }\end{array}$ \\
\hline Conscientiousness & $\begin{array}{l}\text { Contrasts aspects commonly associated with character such as self- } \\
\text { disciplined and organized with impulsivity and disorganization }\end{array}$ \\
\hline
\end{tabular}

Each of the five factors of the FFM is comprised of six facets (see Table 2). Facet scores are produced by responses to eight item statements per facet on the NEO-PI-R. Scores from the eight-item statements associated with each facet are totaled resulting in the facet scores. The six facet scores comprising each factor are totaled resulting in the factor scores. The suggestion has been made that the narrow facets might increase the robustness of factor findings and may increase the ability of the FFM to predict performance (Costa, McCrae, \& Kay, 1995; Paunonen \& Ashton, 2001).

Table 2

The Facets of the Five-Factor Model

\begin{tabular}{|l|l|l|l|l|}
\hline Neuroticism & Extraversion & Openness & Agreeableness & Conscientiousness \\
\hline Anxiety & Warmth & Fantasy & Trust & Competence \\
\hline Angry Hostility & Gregariousness & Aesthetics & Altruism & Order \\
\hline Depression & Assertiveness & Feelings & Compliance & Dutifulness \\
\hline $\begin{array}{l}\text { Self- } \\
\text { Consciousness }\end{array}$ & $\begin{array}{l}\text { Excitement- } \\
\text { Seeking }\end{array}$ & Actions & Straightforwardness & $\begin{array}{l}\text { Achievement- } \\
\text { Striving }\end{array}$ \\
\hline Impulsiveness & Activity & Ideas & Modesty & Self-Discipline \\
\hline & $\begin{array}{l}\text { Positive } \\
\text { Vulnerability }\end{array}$ & Emotions & Tender-Mindedness & Deliberation \\
\hline
\end{tabular}

Note. Source of facet labels (Costa \& McCrae, 1992).

A review of the factors and facets of the FFM might suggest certain trait levels that could predict job performance overall and with experienced U.S. Army rotary-wing aviators in particular. High Neuroticism would be expected to have a negative correlation with high performance with Army rotary-wing aviators. However, Conscientiousness and Agreeableness 
would seem to be related to performance outcomes since Army aviators are required to function as members of small, task-oriented groups or aircrews and within highly technical environments where a high degree of competence must be maintained in order to mitigate the risks that often surround an aircrew work environment.

The FFM has received empirical support for its broad coverage of personality traits (e.g., Barrick \& Mount, 1991; Barrick et al., 2001; Digman, 1989; 1990; Goldberg, 1981). The FFM taxonomy has received support from other personality instruments (Goldberg, 1990; Helton \& Street, 1993). Support for this model includes substantial heritability (Jang, McCrae, Angleitner, Riemann, \& Livesly, 1998) and consistency across cultures (Avdeyeva \& Church, 2005; Caprara, Barbaranelli, Borgogni, \& Perugini, 1993; John, Goldberg, \& Angleitner, 1984; John \& Srivastava, 1999; Paunonen, Jackson, Trzebinski, \& Forsterling, 1992: Trull \& Geary, 1997; Tsaousis \& Nikolaou, 2001) as well as "some fairly consistent relationships between dimensions of the five factor model and job performance" (Barry \& Stewart, 1997, p. 63). This discussion of FFM research focuses on findings related to person-environment fit, performance, and military research.

The FFM and Workplace Performance. The FFM has been successful in predicting performance in numerous studies with various performance criteria and across different types of vocations (e.g.., Barrick \& Mount, 1991; Digman, 1989, 1990; Mount et al., 1998; Tett \& Burnett, 2003; Waldman et al., 2004). For example, Conscientiousness has been predictive of job proficiency and personnel data (e.g., salary, turnover) and combined with Extraversion and Openness to predict training proficiency in a diverse occupational sample (e.g., professionals, police, managers) (Barrick \& Mount, 1991). The FFM has been linked to the likelihood of promotion, salary level, and career satisfaction (Barrick et al., 2003; Ostroff \& Rothausen, 1997; Seibert \& Kraimer, 2001). Barrick et al. (2001) examined FFM findings from 15 meta-analytic studies and reported that: (a) Conscientiousness is a valid predictor across all performance measures; (b) Emotional Stability (low Neuroticism) was significant when work performance was the criterion; and (c) the remaining factors (Extraversion, Agreeableness, and Openness) were predictors of success in specific occupations such as those involving teamwork.

Teamwork is a performance concern that has been given attention over the past two decades as organizations are increasingly relying upon teams to perform tasks and accomplish goals. Group dynamics research has investigated connections between FFM traits and group performance. Mount et al. (1998) found that the FFM factors of Conscientiousness, Agreeableness, and Emotional Stability (i.e., low Neuroticism) were positively related to jobs requiring interpersonal interactions, and Emotional Stability and Agreeableness were strongly related to jobs requiring teamwork. Barry and Stewart (1997) found in their study of 61 fourand five-person problem-solving groups that Extraversion was the primary factor that influenced individual input into the group and that determined group output.

The FFM and Person-Environment Fit. The theoretical foundation of this investigation is grounded in the assumption of person-environment (P-E) fit theory. That is, creating perceptions of congruence between individual qualities (e.g., personality traits, interests, abilities) and the inherent characteristics of an occupation or a workplace environment will result in desired work outcomes (e.g., improved performance, higher perceived job satisfaction, tenure) 
(Assouline \& Meir, 1987; Barrick et al., 2003; Edwards, 1996; Kieffer, Schnika, \& Curtiss, 2004; Latham \& Pinder, 2005; O'Reilly, Chatman, \& Caldwell, 1991; Ostroff \& Rothausen, 1997; Schneider, 1983; 1987; Schmitt, Cortina, Ingerick, \& Wiechmann, 2003).

Studies have revealed a link between FFM traits and perceptions of P-E fit. For example, Judge and Cable (1997) compared the FFM personality profiles of 182 business, engineering, and industrial relations students who were also jobseekers with their preference for types of organizational cultures. They found that respondents with high Neuroticism scores were less attracted to innovative and decisive organizational cultures. Those with high Extraversion scores were attracted to aggressive and team-oriented organizational cultures. High Openness scores were more likely to choose innovative and autonomous organizational cultures. Respondents scoring high on Agreeableness were more attracted to supportive and team-oriented organizational cultures. High Conscientiousness was predictive of choosing detail-oriented, outcome-oriented, and rewards-oriented organizational cultures.

Correlations have been reported between P-E fit instruments such as Holland's (1985a; 1985b, respectively) Self Directed Search (SDS) and the Vocational Preference Inventory (VPI) and the FFM. The SDS and VPI are based on Holland's (1973; 1978; 1985a; 1985b) RIASEC taxonomy that categorizes occupations as Realistic, Investigative, Artistic, Social, Enterprising, and Conventional. Modest correlations have been found between the factors and facets of the FFM and Holland's RIASEC taxonomy (Kieffer et al., 2004; Larson, Rottinghaus, \& Borgen, 2002; Schinka, Dye, \& Curtiss, 1997; Sullivan \& Hansen, 2004). Kieffer et al. reported correlations between Social and Agreeableness $(r=.207, p<.01)$, Artistic and Openness $(r=$ $.462, p<.01)$, Conventional and Conscientiousness $(r=.204, p<.01)$, Enterprising and Extraversion $(r=.528, p<.01)$. Larson et al. reported similar FFM-RIASEC correlations: (a) Artistic - Openness $(r=.48)$; (b) Investigative - Openness $(r=.28)$; (c) Enterprising Extraversion ( $r=.41)$; (d) Social - Extraversion $(r=.31)$; and (d) Social - Agreeableness ( $r=$ .19). Barrick et al. (2003) reported similar findings as Larson et al. with the additional finding that Conscientiousness was related to Conventional interests.

The correlations between the FFM and Holland's instruments seem to argue for the value of including the FFM in selecting and placing employees. The FFM has been offered as possibly the best approach for employers to use in determining P-E fit in employment selection and placement decisions (De Fruyt \& Mervielde, 1999; Furnham, 2001). Salgado (2003) proposed that FFM-based instruments are possibly more productive in personnel decisions because these measure Conscientiousness and Emotional Stability which have generalized validity across occupations, organizations, criteria, and cultures. He concluded, “... these findings suggest that FFM-based inventories improve the validity of personality measures (at least for conscientiousness and emotional stability) and that this is probably due to the construct validity of those inventories" (p. 333).

\section{Personality and Performance}

The American Heritage Dictionary (1994, p. 619) defines personality as "the totality of qualities and traits, such as character or behavior, that are peculiar to a specific person." Personality traits are defined as "stable, deep-seated predispositions to respond in particular ways" (Chidester, Helmreich, Gregorich, \& Geis, 1991, p. 27). McCrae and Costa (1990) 
defined traits as "dimensions of individual differences in tendencies to show consistent patterns of thoughts, feelings, and actions" (p. 23). A trait emphasis in defining personality typically conceptualizes personality as consisting of genetically-based predispositions or characteristics (temperaments) that tend to remain constant across much of the lifespan, but that can be influenced by environmental factors such as social desirability and the requirements of performing social roles (Caspi, Roberts, \& Shiner, 2005).

A benefit of utilizing a trait framework in describing personality is that potential relationships can be explored between personality traits and other variables such as job performance. Numerous studies have found that a connection can be identified between personality traits and workplace outcomes (e.g., performance, job satisfaction, tenure) (e.g., Barrick \& Mount, 1991; Judge, Heller, \& Mount, 2002; Mount et al., 1998). Aviation research has been generally supportive of a relationship between personality traits and cockpit performance (Anesgart \& Callister, 2001; Callister et al., 1997; Gregorich, Helmreich, Wilhelm, \& Chidester, 1989; Helmreich \& Wilhelm, 1989). The goal of this literature review was to provide a research foundation that will contribute to providing a rationale for using the FFM with U.S. Army rotary-wing aviators.

Personality research has typically supported a relationship between personality traits and performance (e.g., Barrick \& Mount, 1991; Judge \& Ilies, 2002). For example, personality traits have been linked with job satisfaction (Judge et al., 2002), training proficiency (Mount \& Barrick, 1998), and performance motivation (Judge \& Ilies, 2002; Latham \& Pinder, 2005). Despite the findings indicating a relationship exists between personality and performance, there has been disagreement expressed over the level of significance in this relationship (e.g., Ghiselli, 1973; Guion \& Gottier, 1965; Schmitt, Gooding, Noe, \& Kirsch, 1984). One reason for the low validities reported in these studies could have been the lack of a well-accepted taxonomy for classifying personality traits. Another reason could be they did not account for the influence of moderator variables on the relationship between personality and performance criterion (Barrick \& Mount, 1993). The result of not using a concise and comprehensive classification system for personality traits was that the findings were likely obscured and difficult to manage (Barrick et al., 2001).

Aircrew teamwork and the efficacy of training are performance concerns for aviation research. Personality has been identified as a factor that could influence teamwork and the effectiveness of aircrew teamwork training (Chidester et al., 1991; Siem \& Murray, 1994). Chidester and colleagues commented, "Selecting individuals on the basis of optimizing the fit between personality characteristics and desired performance may prove highly beneficial" (p. 41).

Personality traits have been used to predict which aviation students will successfully complete flight training (Anesgart \& Callister, 2001; Helton \& Street, 1993). Anesgart and Callister found that high Neuroticism coupled with low Extraversion indicated an aviator was ten times more likely to self-eliminate from flight school, while very high Neuroticism coupled with very low Extraversion indicated an aviator was 50 times more likely to self-eliminate from flight school. Callister et al. (1997) suggested that facet scores should be considered in predicting performance, such as a low score on Achievement Striving as a possible indicator of low motivation to accomplish a task under stressful conditions such as would be found in aviation 
training. Chidester et al. (1991) found that personality influenced the effectiveness of training aimed at improving interpersonal relations or coordination in the cockpit, with pilots reporting personality traits comprising a Positive Instrumental/Expressive profile benefiting most from training and those with traits comprising a Low Motivation profile benefiting least from training.

Aviator performance has been construed as a product of attitude, skills, and personality factors (Chidester et al., 1991). Personality has been found to influence decision-making (Murray, 1999) and the likelihood of experiencing an aviation mishap (Lardent, 1991). Personality can influence leadership styles and communication in the cockpit (Kanki et al., 1991). Kanki and Palmer (1993) emphasized the role of personality in cockpit performance by commenting, "One important input to the interpersonal-communication-performance formula is the personality of each individual making up the crew. The separate personalities of crewmembers must be integrated to create a single, effective, team with a positive orientation toward sharing tasks and information relevant to those tasks" (p. 116).

The personality traits relevant to aviator performance include those that apply to the tasks and those that influence interpersonal dynamics between crewmembers. Chidester and associates (1991) proposed that the influence of personality on performance involves two dimensions: (a) instrumental traits such as goal-seeking and achievement motivation; and (b) expressive traits such as interpersonal behaviors and sensitivity. They found that traits related to instrumentality (e.g., goal orientation, independence) and expressivity (e.g., interpersonal warmth) are predictors of team performance in the cockpit. Shinar (1995) found three personality characteristics had an influence on pilot achievement: (a) a high need for achievement; (b) self-assertiveness and a willingness to face difficulties to fulfill the need; and (c) a positive self-identity that remains stable regardless of cockpit experiences.

Military Performance. Personality research with U.S. Army rotary-wing aviators is limited and dated. The most recent of the three studies retrieved was from 1993. None of these studies used the NEO-PI-R, probably because it was published in 1992. Since its original publication, the NEO-PI-R has become one of the most frequently used personality instruments in studies seeking to disclose a link between personality and performance. A review of the three studies involving Army rotary-wing aviators provides some insight into this special population.

Geist and Boyd's (1980) study is the oldest study retrieved from the literature search. Geist and Boyd administered the MMPI to 15 male Army helicopter aviators and 16 male nonaviation U.S. Army officers. The aviators were found to report more pathology than nonaviators, with higher scores in hypochondriasis $(H S)$, depression $(D)$, psychasthenia $(P t)$, and hysteria $(H y)$. They also reported high scores on social introversion $(S i)$. While this investigation provides a snap-shot of Army rotary-wing aviator personality traits, it fails to suggest grounds for creating a sense of congruence between identified personality traits and mission platform characteristics.

Picano (1991) surveyed 170 U.S. Army rotary-wing aviators in the only reported study to consider the possibility of personality traits clustering differently among aircraft. Picano was seeking to validate the Occupational Personality Questionnaire with Army aviators and found three personality clusters across subjects similar to Retzlaff and Gibertini (1987). The largest 
cluster (48\%) resembled those traits stereotypically ascribed to military aviators. Picano labeled this group the "methodical extroverts" and they corresponded to Retzlaff and Gibertini's "company-man." That is, they were outgoing and used a structured problem-solving approach emphasizing planning, logical analysis, and attention to detail. They were also concerned with maintaining a positive image as an aviator that would reflect positively on the U.S. Army.

The second cluster (36\%) were emotionally controlled, inhibited, and appeared apprehensive. They tended to prefer stability and predictability, and were uncomfortable in social situations. Picano (1991) labeled this group as "introverted worriers" and they would correspond with Retzlaff and Gibertini's (1987) "wrong stuff." This group would be the ones most likely to exit from military aviation.

The final cluster was the smallest group (16\%) of aviators and corresponded with Retzlaff and Gibertini's (1987) "right stuff." Picano (1991) labeled this group as "competitive individualists." Aviators in this cluster were described as highly independent, competitive, and decisive. In terms of low scores they were found to be least emotionally sensitive and exhibited the lowest concern for making a good impression. Picano expressed some degree of surprise that many instructor pilots (IPs) were part of this cluster. His explanation was that IPs likely represent high competitiveness and are achievement-oriented because it is required for them to achieve this status.

Picano's (1991) study did not reveal marked differences in personality across mission platforms. However, he recommended that further personality research with Army aviators is needed. He concluded:

The typological approach to studying pilot personality may establish an empirical foundation for new practical applications of personality assessment in aviation including selection and classification, instructor/student matching and crew composition which might serve to reduce training costs, improve performance, and enhance aviation safety. (Picano, 1991, p. 520)

Picano determined that he was unable to provide an overall aviator personality profile based upon his findings.

Caldwell and associates (Caldwell, O'Hara, Caldwell, Stephens, \& Krueger, 1993) found differences between U.S. Army aviators applying to Special Operations training and those remaining in general aviation using the MMPI. They compared the personality traits of conventional helicopter aviators $(n=58)$ with those seeking Special Operations $(n=229)$ duty. Their findings indicated overall personality differences for both groups in comparison with the general public in descriptions such as personal defensiveness, extraversion, nonconformity, friendliness, and sociability. The authors reported that personality findings between those choosing conventional aviation and those applying for Special Operations training were of limited interpretive value. For example, there were differences reported between the two groups on the MMPI scales of Hysteria (Hy), Psychopathic Deviant $(P d)$, Hypomania (MA), and Social Introversion $(\mathrm{Si})$. However, the authors offered that inter-group differences on the clinical Masculinity-Femininity $(M f)$ scale and the test-taking $(K)$ validity scale were probably the most 
helpful in identifying the personality differences they were seeking between these two groups of aviators.

The conventional aviators scored higher on the $M f$ scale than the Special Operations sample suggesting perceptions of a greater sense of balance between characteristics associated with masculinity and femininity for those pursuing conventional aviation. The authors concluded that conventional aviators are similar to college-educated males in that they are often more passive, aesthetically-oriented, and indirect in problem solving than those pursuing Special Operations training. The Special Operations group was found to be more like stereotypical males being somewhat traditional and inflexible.

Differences on the $K$ scale were linked with $M f$ scores in that they were interpreted in terms of the level of traditional masculinity. Caldwell et al. (1993) found that the Special Operations group answered questions "less deviantly and in a more stereotypically male fashion, although they appeared less impulsive, slightly more extraverted, and more defensive" (p. 197). The authors proposed that the combination of scales $K$ and $M f$ were the best predictors of group membership for these aviators because of the traits measured by these scales. For instance, the high $K$ scores for the Special Operations group were compared to the characteristics of aviators posited by Ursano (1980) that included (a) avoiding introspection, (b) denying internal emotional events, and (c) being self-sufficient.

The same is true for lower $M f$ scores from the Special Operations group since these indicate a greater propensity for behaviors associated with traditional perceptions of masculinity. The authors suggested that it seems reasonable to assume that Special Operations aviators would demonstrate these characteristics more than conventional aviators. While these findings are helpful in understanding the differences in masculinity between types of aviators, their benefit is limited in providing detailed insight into the personality profiles of Army rotary-wing aviators.

Three shortcomings appear to befall what is currently known about Army rotary-wing aviator personalities. First, reported personality studies involving Army rotary-wing aviators are over a decade old. Changes in aviation technology and in the operational conditions where Army aviators are called upon to fly might indicate that a different set of characteristics such as personality traits are needed today. Second, there are a minimal number of reported studies available. The present investigation is designed to contribute to this personality research with Army aviators and will use the NEO-PI-R for the first reported time. Third, no single approach to personality has been identified as the most comprehensive to use with Army rotary-wing aviators. This investigation could provide initial support for using the NEO-PI-R in future research with Army aviators.

The FFM and Military Performance. The applicability of the FFM in predicting performance and in encouraging P-E fit has been recognized in military research. Military research has considered the viability of using the FFM approach to personality in leadership performance, personnel placement, and as a predictor of training success. FFM factors have been linked with leadership performance. For instance, Vickers (1995) used the NEO-PI-R with U.S. Navy personnel and identified positive leadership qualities including competence, effort, achievement striving, self-discipline, frankness, trust, assertiveness, and aggressiveness. In all, 
four of the five FFM factors (excluding Neuroticism) are represented in Vickers' findings. Vickers concluded that the NEO-PI-R is a suitable instrument for selection purposes.

Ployhart, Lim, and Chan (2001) studied 1,259 East Asian military officers comparing multiple ratings of typical and maximum performance. They found that Openness was predictive of maximum performance and Neuroticism scores were predictive of typical performance. Extraversion scores were found to be predictive of typical and maximum performance. Ployhart et al. concluded that the effect size for the FFM constructs was stronger for maximum performance, indicating personality likely is predictive of transformational leadership under stressful conditions.

The FFM has been applied in military studies seeking to improve personnel placement (King, Retzlaff, Detwiler, Schroeder, \& Broach, 2003; Pedersen, Allan, Laue, Johnson, \& Siem, 1992; Street, Helton, \& Nontasak, 1994). The NEO-PI-R has been found to improve the selection of air traffic control specialists, especially with the factor of Conscientiousness (King, et al., 2003,). NEO-PI-R findings were predictive of success for Landing Craft Air Cushion Vehicle training with Openness exhibiting the greatest correlation with performance (Street et al., 1994). A possible explanation is that Openness may contribute to academic performance and increase the likelihood of successfully mastering the detailed procedures involved in training.

U.S. Army aviation provides regular training designed to improve skills and teamwork in the cockpit. Some consideration has been given to investigating the influence personality traits might have on training success. For instance, Chidester et al.'s (1991) comment, "Although it is encouraging that efforts are now underway to improve both the technical and interpersonal skills dimensions, considering the impact of other dimensions such as stable personality characteristics, may make an additional contribution to optimizing crew performance" (p. 26).

Studies have found that FFM factors can predict training proficiency and outcomes (Barrick \& Mount, 1991; Mount \& Barrick, 1998). For example, Conscientiousness and Openness have been positively associated with a goal orientation for learning (Klein \& Lee, 2006). McCormack and Mellor (2002) studied 99 Australian military officers to see if their personality traits predicted which officers would be selected for a promotion course. They found that high Conscientiousness and Openness combined with low Extraversion predicted the likelihood of being selected for the course.

\section{Rationale for Using the FFM in this Investigation}

Research has indicated that two essential elements should be considered in personalityperformance research (Driskell, Hogan, \& Salas, 1987). First, a comprehensive model of personality structure and measurement should be adopted. The FFM has received validation in numerous studies as a comprehensive model of personality (Barrick \& Mount, 1991; Costa \& McCrae, 1985). Barry and Stewart (1997) comment, "Although there remains disagreement and dissent on the structure and measurement of personality, the development and validation of the five factor model approach to personality offers a broad-based, empirically manageable, and demonstrably relevant avenue for examining personality in work organizations" (p. 62-63). 
A consideration in determining which comprehensive model of personality should be used with aviators is to review the research and to see which model appears to be the most valid with this population. Reviews of personality models and instruments in relation to aviator performance have produced mixed results (Davis, 1989; Hilton \& Dolgin, 1991). For example, Dolgin \& Gibb (1988) expressed disappointment in their review of a dozen personality instruments because none of them demonstrated strong predictive validity in aviator selection. They did not include a FFM-based instrument in their review. Helton and Street (1993) proposed that failing to link personality with performance might be because, "researchers were addressing only a portion of a more comprehensive description of personality" (p. 9).

Findings have been more promising in studies employing the FFM (Bartram, 1995; Callister et al., 1997; Fitzgibbons et al., 2004). Support has been reported for linking the FFM with performance including predicting the likelihood of attrition from flight training (Anesgart \& Callister, 2001) and the emergence of undiagnosed psychological problems during flight training (Callister et al., 1997). Pedersen et al. (1992) concluded the FFM was likely the best approach for the USAF to use in aircrew selection decisions based upon their review of 13 personality theories. Helton and Street (1993) found that the personality results with U.S. Navy aviators using other personality instruments could be categorized according the factors of the FFM.

Second, the instrument used should measure traits prominent within a normal population rather than traits measuring psychopathology (Callister et al., 1997). A bright spot in the research has been the creation of positive, performance-based measures, such as the NEO-PI-R, that have proven to be more accurate descriptors and predictors of personality (Dolgin et al., 2002; King, 1994; King et al., 1997). The NEO-PI-R is the most commonly used instrument measuring FFM factor and facet levels (Bernard \& Walsh, 2004). The NEO-PI-R is "highly regarded for its ability to gauge normal personality functioning" (King \& Flynn, 1995, p. 955).

The rationale for surveying experienced U.S. Army rotary-wing aviators is that they might reveal personality trait levels that contribute to perceptions of congruence with Army aviation and with each of the four mission platforms. While performance and tenure by Army aviators is not determined solely by personality, personality traits may contribute to perceptions of congruence between aviators and the workplace environment of Army aviation. An instrument such as the NEO-PI-R that is based on a comprehensive but simple taxonomy and that is normed for the general population appears to provide the best solution as an instrument to use in identifying the personality traits of experienced Army aviators.

\section{Research Questions}

The first purpose of this investigation was to identify the personality profiles of experienced U.S. Army rotary-wing aviators based upon the personality factors of the FFM. Additionally, this investigation sought to determine if the personality trait levels of these aviators were significantly different across the Army's four rotary-wing mission platforms (i.e. Attack, Scout/Observation, Cargo, and Utility). Two research questions were examined in this investigation 
- Research Question \#1: What are the personality profiles of experienced U.S. Army rotary-wing aviators?

- Research Question \#2: Do experienced U.S. Army rotary-wing aviator personality profiles differ significantly across the U.S. Army's four mission platforms?

Research Design

Sample

Ninety survey packets were originally provided for qualified U.S. Army rotary-wing aviators attending advanced leadership training at the Warrant Officer Career Center (WOCC) located at Fort Rucker, Alabama from October 2005 to January 2006. Seventy-seven survey packets were returned, but two were incomplete and were not included in the sample $(n=75)$. Experienced aviators were surveyed because they presumably represent those with a good P-E fit within Army aviation. Another advantage of surveying experienced aviators is that it will likely mitigate the "Honeymoon Effect" (Helmreich, Sawin, \& Carsrud, 1986) since experienced aviators should have a more accurate or realistic understanding of the workplace dynamics found in Army aviation. Surveyed aviators had achieved the military rank of Chief Warrant 3 (CW3), Chief Warrant 4 (CW4), or Chief Warrant 5 (CW5).

\section{Instruments}

A demographic form was created for this investigation. The data collected pertained to general demographic information such as age, gender, rank, time in rank, and years of military service. Specific questions related to aviation included years of aviation experience, preferred aircraft, and job satisfaction. Subjects were asked to identify their initial aircraft and if they had been classified in a different aircraft during their career. Names and identifying numbers (e.g., Social Security Numbers) were not requested in order to protect confidentiality.

The NEO-PI-R was used to measure personality. It is the most commonly used instrument for measuring FFM domains (Bernard \& Walsh, 2004). The NEO-PI-R has been used across numerous types of vocations to identify a link between personality and job performance. Costa and McCrae (1997) revisited the factors and facets of the NEO-PI-R to consider if the instrument needed large-scale changes in structure or terminology and concluded, "We do not imagine that the FFM is the last word in personality structure, but we do believe that it will remain the basis of personality assessment for many years" (p. 87).

Structure. The NEO-PI-R is a 240 -item self-report questionnaire to which subjects respond to statements on a scale of 0 (strongly disagree) to 4 (strongly agree) and scores range from very low to very high with descriptors representing each end of the spectrum. Factor and facet scores were generated for the sample. Facet scores can increase the richness of findings (Paunonen \& Ashton, 2001), but the focus of this investigation was on factor-level findings. Studies exploring facet-level differences appear to hold merit as future research.

Reliability. Costa and McCrae (1992) reported high test-retest and internal consistency reliability. For example, reliability for the NEO-PI-R was reported based upon the findings of 
Costa, McCrae, and Dye's (1991) employment study consisting of 1,800 male and female employees. Internal consistency was supported with coefficient alphas of the FFM domains ranging from .86 to .92 . Internal consistency for facet scales ranged from .56 to .81 .

Test-retest reliability was reported by Kurtz and Parrish (2001). They examined the testretest scores on the NEO-PI-R among three groups of respondents categorized as low, moderate, or high in inconsistent responding (INC) during the initial administration of the NEO-PI-R. This determination was based upon one of the NEO-PI-R validity scales offered by Schinka, Kinder, and Kremer (1997). Test-retest correlations for each group were found to be high across FFM domains based upon self-report and informant data. Low INC group correlations ranged from .92 to .95 on self-report data and from .75 to .93 on informant data. The moderate $\mathrm{NC}$ group reported correlations ranging from .85 to .95 on self-report data and informant data correlations ranged from .73 to .82 . The high INC group reported correlations ranging from .71 to .94 on self-report data and ranged from .66 to .92 on informant data.

Kurtz, Lee, and Sherker (1999) provided support for the reliability for the NEO-PI-R. Their test-retest protocol with undergraduate students over a 6-month period resulted in high correlations. Initial domain coefficient alphas ranged from .89 to .96 , with a median of .80 on the facet scales. Test-retest Pearson correlations exceeded .70 for each domain.

Validity. The NEO-PI-R has received some criticism for not including validity scales (Ben-Porath \& Waller, 1992; Bernard \& Walsh, 2004; Butcher \& Rouse, 1996; Schinka, et al., 1997). Research generally supports the validity and reliability of the NEO-PI-R even in the absence of validity scales (McCrae \& Allik, 2002; McCrae, Costa, del Pilar, Rolland, \& Parker, 1998; McCrae, Zonderman, Costa, Bond, \& Paunonen, 1996). The authors (Costa \& McCrae, 1992) of the NEO-PI-R contend that validity scales are not necessary because validity checks are in place, including (a) the proper administration of the instrument, (b) judicious interpretation of responses should result in valid test results, and (c) three statements at the bottom of the answer sheet asking respondents if they answered honestly, completely, and correctly.

Much of the concern expressed over a lack of validity scales focuses on test-faking and non-purposeful responding (Rosse, Stecher, Miller, \& Levin, 1998; Scarpello, Ledvinka, \& Bergmann, 1995). Findings thus far do not indicate that test-faking is a problem with the NEOPI-R. The suggestion has been made that strategies be developed that will mitigate the threat of test-faking (Barrick \& Mount, 1996; Ellingson, Smith, \& Sackett, 2001; Hough, Eaton, Dunnette, Kamp, \& McCloy, 1991). For example, Holden and Hibbs (1995) measured response latency as an indication of faking responses. Hogan (2005) offered that test-faking should not be a concern because: (a) many respondents lack the capacity to "improve" test scores; (b) respondents do not typically know what the desired response should be; and (c) evaluations of personality scores usually only consider a small portion of findings rather than the entire profile.

The validity of the NEO-PI-R has been supported in correlational studies with other validated personality instruments. Studies have found significant correlations between the NEOPI-R and other personality instruments such as the Myers-Briggs Type Indicator (MBTI; Myers \& McCauley, 1985), the MMPI, and the Wechsler Adult Intelligence Scale - Revised (WAIS-R; Wechsler, 1981). Furnham, Moutafi, and Crump (2003) reported significant correlations 
between the NEO-PI-R factors of Extraversion, Openness, Agreeableness, and Conscientiousness and the MBTI factors of Extraversion-Introversion, Sensing-Intuition, Thinking-Feeling, and Judging-Perceiving respectively. Costa, Busch, Zonderman, and McCrae (1986) found significant correlations between MMPI factors and the FFM domains measured in the NEO-PI-R, especially within a normal sample. Significant correlations were also reported between Openness and IQ scores on the WAIS-R (Holland, Dollinger, Holland, \& MacDonald, 1995).

The validity of the FFM has also been supported in cross-cultural studies. FFM-based instruments such as the NEO-PI-R have been translated into languages other than English. For instance, personality findings with Chinese (Trull \& Geary, 1997), Greek (Tsaousis \& Nikolaou, 2001), and Filipino (Avdeyeva \& Church, 2005) samples have supported the validity of the FFM factors. The applicability of the FFM across cultures appears to diminish concerns over cultural bias. The authors of the NEO-PI-R have found sufficient validity with the instrument and with the FFM that scores are not normed based upon ethnicity. Scores are, however, normed based upon gender.

\section{Procedures}

Survey packets were delivered to WOCC training personnel for distribution and collection. Survey packets consisted of two informed consent forms, one demographic form, and one paper-and-pencil version of the NEO-PI-R instrument and answer sheet. All materials were to be returned except for one copy of the informed consent form. A random number was assigned to the materials in each packet in order to match the demographic information with NEO-PI-R scores.

Answer sheets were hand-scored and scores were entered into a spreadsheet created in the Statistical Package for the Social Sciences (SPSS) structure. A random sample of the handscored portion of the answer sheets was re-scored to mitigate risks of calculation errors. Statistical analyses were conducted using SPSS.

Findings

\section{Demographics}

Demographic findings revealed a mean age of $45(S D=6.11)$ for the sample.

Respondents were all male and ethnicity was not reported since NEO-PI-R norms are not based on ethnicity. Respondents reported a mean of 24 years $(S D=6.42)$ of military service and a mean of 20 years $(S D=6.50)$ of aviation experience. The mean years at current rank was 6 years $(S D=4.32)$. The majority $(53.6 \%)$ of the sample chose their initial aircraft while the remaining (46.4\%) respondents were assigned to their initial aircraft by the Army independent of their personal preferences. The initial aircraft most frequently chosen or assigned was Utility (61.6\%), followed by Attack (21.9\%), Scout/Observation (13.7\%), and Cargo (2.7\%).

The majority of respondents (69\%) reported acquiring additional qualifications to fly a different aircraft at some point in their career. This additional aircraft qualification occurred, on 
average, around seven years into their aviation careers. The most frequent reason for the change of aircraft was involuntary reassignment by the Army (37.5\%). This was followed by a desire for career advancement (33.3\%) and a desire to fly a different aircraft $(29 \%)$.

Job satisfaction was almost unanimously reported $(n=74)$ by this sample. Only one respondent reported not being satisfied with his current aircraft assignment. Subjects were asked to identify their preferred type of aircraft or mission platform and this selection determined which mission platform would be their designation for this investigation. The most frequently chosen "preferred aircraft" was Utility (53.3\%), followed by Attack (21.3\%), Scout/Observation (14.7\%), and Cargo (10.7\%).

\section{Research Question \#I}

The first research question (i.e., What are the personality profiles of experienced U.S. Army rotary-wing aviators?) yielded the identification of a personality profile for the total sample of experienced Army rotary-wing aviators. The personality profiles are based upon the NEO-PI-R factor scores collected in this investigation. Table 3 presents the descriptive statistics for the total sample. Table 4 presents total sample factor scores and scores across mission platforms. Mean scores of the sample were compared with NEO-PI-R norms (Costa \& McCrae, 1992) to determine if they ranked "low," "average," or "high." Table 5 provides the ranking of factor scores across mission platforms.

Table 3

Descriptive Statistics of Total Sample NEO-PI-R Factor Scores

\begin{tabular}{lrrrrr}
\hline & & & & & \\
& $N$ & $E$ & O & AG & \multicolumn{1}{c}{ CO } \\
\cline { 2 - 6 } Number & & & & & 75 \\
Mean & 75 & 75 & 75 & 75 & 75 \\
Median & 62.77 & 116.55 & 98.47 & 116.51 & 132.91 \\
Mode & 63.00 & 117.00 & 99.00 & 117.00 & 133.00 \\
Std. Dev. & 65.00 & 105.00 & 82.00 & 121.00 & 133.00 \\
Skewness & 18.54 & 18.59 & 17.43 & 16.25 & 18.09 \\
\hline
\end{tabular}

Note. Factor names: $\mathrm{N}=$ Neuroticism; $\mathrm{E}=$ Extraversion; $\mathrm{O}=$ Openness; $\mathrm{AG}=$ Agreeableness; $\mathrm{CO}=$ Conscientiousness. Average normative range of scores from Costa \& McCrae (1992): Neuroticism (65-86); Extraversion (99-118); Openness (101-119); Agreeableness (112-128); Conscientiousness (115-133). 
Table 4

Comparison of Total Sample and Mission Platform Scores

\begin{tabular}{lcccccccccc}
\hline Factor & \multicolumn{1}{c}{$\begin{array}{c}\mathrm{A} \\
(n=16)\end{array}$} & \multicolumn{2}{c}{$\begin{array}{c}\mathrm{S} / \mathrm{O} \\
(n=11)\end{array}$} & \multicolumn{2}{c}{$\begin{array}{c}\mathrm{C} \\
(n=8)\end{array}$} & \multicolumn{2}{c}{$\begin{array}{c}\mathrm{U} \\
(n=40)\end{array}$} & \multicolumn{2}{c}{$\begin{array}{c}\text { TS } \\
(n=75)\end{array}$} \\
\hline & $M$ & $S D$ & $M$ & $S D$ & $M$ & $S D$ & $M$ & $S D$ & $M$ & $S D$ \\
$\mathrm{~N}$ & 68.75 & 18.73 & 66.55 & 14.85 & $60^{*}$ & 17.11 & $59.78^{*}$ & 19.47 & $62.77^{*}$ & 18.54 \\
$\mathrm{E}$ & 114.38 & 14.45 & 114.09 & 20.82 & 118 & 21.53 & 118.03 & 19.60 & 116.55 & 18.59 \\
$\mathrm{O}$ & $94.88^{*}$ & 15.41 & $97.73^{*}$ & 17.38 & $97.75^{*}$ & 16.98 & $100.13^{*}$ & 18.66 & $98.47^{*}$ & 17.43 \\
$\mathrm{AG}$ & $103.81^{*}$ & 17.95 & 114.46 & 10.22 & 113.50 & 13.15 & 122.70 & 14.53 & 116.51 & 16.25 \\
$\mathrm{CO}$ & $137.06^{* *}$ & 14.78 & 127.55 & 20.41 & 129.13 & 19.22 & $134.38^{* *}$ & 17.82 & 132.91 & 18.09 \\
\hline
\end{tabular}

Note. * denotes "low" and ** denotes "high" ranking of scores based upon NEO-PI-R norms. Mission Platform names: $\mathrm{A}=$ Attack; $\mathrm{S} / \mathrm{O}=$ Scout/Observation; $\mathrm{C}=\mathrm{Cargo} ; \mathrm{U}=\mathrm{Utility}$; $\mathrm{TS}=$ Total Sample. Factor names: $\mathrm{N}=$ Neuroticism; $\mathrm{E}=$ Extraversion; $\mathrm{O}=$ Openness; $\mathrm{AG}=$ Agreeableness; $\mathrm{CO}=$ Conscientiousness.

Table 5

Ranking of Factor Scores Across Mission Platforms

\begin{tabular}{lrrrrr}
\hline & & & & & \\
Factor & A & S/O & C & U & Total Sample \\
\hline$n$ & 16 & 11 & 8 & 40 & 75 \\
Neuroticism & Average & Average & Low & Low & Low \\
Extraversion & Average & Average & Average & Average & Average \\
Openness & Low & Low & Low & Low & Low \\
Agreeableness & Low & Average & Average & Average & Average \\
Conscientiousness & High & Average & Average & High & Average \\
\hline
\end{tabular}

Note. Mission Platform names: $\mathrm{A}=$ Attack; $\mathrm{S} / \mathrm{O}=$ Scout/Observation; $\mathrm{C}=$ Cargo; $\mathrm{U}=\mathrm{Utility}$. Rankings based upon NEO-PI-R norms provided by Costa and McCrae (1992).

Specific descriptions are provided by Costa and McCrae (1992) to help clarify the factor score rankings. For example, low Neuroticism would involve characteristics such as being emotionally stable and calm under stress. Average Neuroticism is described as being typically emotionally calm and able to mitigate stress, but there can be occasional experiences with guilt or anxiety. High Neuroticism is typically described as emotional instability such as with experiencing persistent feelings of anxiety or symptoms of depression. 
Total Sample. Based upon the characteristics associated with the rankings of low, average, and high, characteristics can be suggested for the total sample and aviators in each mission platform. The total sample scored low to average across the five factors. The low scores were near the average range, suggesting that this sample of aviators was similar to the personality trait levels of the general public. For instance, NEO-PI-R norms begin the average range for males on the Neuroticism scale at 65 and on the Openness scale at 101. Aviators in this sample were in the low range on Neuroticism $(M=62.77)$ and on Openness $(M=98.47)$.

Low Neuroticism would indicate this group is emotionally stable and able to manage stress. Low Openness would suggest these aviators are practical and conventional and generally obey the established rules or policies. Low Neuroticism coupled with low Openness would seem to suggest that these aviators are able to mitigate the influence of stress in the cockpit and prefer to obey standard operating procedures rather than engage in efforts to create novel approaches to cockpit decision-making.

The remaining factor scores were in the average range. Average Extraversion indicates these aviators are moderately social and active, but value their privacy. Average Agreeableness suggests these aviators are generally warm and cooperative, but can be competitive. Average Conscientiousness indicates these aviators are dependable and moderately goal-oriented, but are able to set work aside for other activities.

\section{Research Question \#2}

The second research question (i.e., Do experienced U.S. Army rotary-wing aviator personality profiles differ significantly across the U.S. Army's four mission platforms?) revealed that this sample of aviators differed on the Agreeableness factor. There were variations in factor score rankings in the aviators across the four mission platforms. For example, Attack and Utility aviators scored in the high range on Conscientiousness while the remaining two groups of aviators were in the average range. One exception was that Openness was low across all four mission platforms, indicating that these aviators are conventional and adhere to procedures rather than actively challenging the status quo with alternative ideas.

It should be noted, however that one of the limitations involved in discussing aviator differences across mission platforms is the wide range in sample size across the four groups (i.e., Cargo [ $[n=8]$, Scout/Observation [ $n=11]$, Attack $[n=16]$, and Utility $[n=40])$. While the overall statistical outcome indicated strong differences across mission platforms on the Agreeableness factor $(p=.001)$, there were variations in group sizes among platforms. There were only eight Cargo aviators. One is reluctant to base conclusions on such small group sizes. Larger group sizes would have been preferable. However, the Analysis of Variance is a robust and powerful analysis, and capable of handling wide discrepancies in group sizes. One of the cautions mentioned by Tabachnick \& Fidell (2001) relates to unequal cell sizes and they state that it is necessary to have more cases than dependent variables in every cell (p. 329). This investigation met that requirement. Nonetheless, it is possible that greater uniformity in sample 
size across the four groups (i.e., mission platforms) of Army aviators could influence findings in future research.

Based upon this sample the following descriptions are offered. Scout/Observation aviators $(n=11)$ scored in the average range on all but the Openness factor, indicating they do not possess personality trait levels that vary from the general public based upon NEO-PI-R norms. Cargo $(n=8)$ and Utility aviators $(n=40)$ were low in Neuroticism, indicating they tend to be emotionally stable, calm, and secure. Conscientiousness was high for Attack $(n=16)$ and Utility $(n=40)$ aviators, suggesting that these respondents may be inclined to be self-disciplined, well-organized, detailed, and goal-oriented. Attack aviators $(n=16)$ were the only ones to deviate from the average ranking in Agreeableness by reporting low on this factor, indicating they might be prone to being hardheaded, direct, and competitive.

Statistical Comparisons. A one-way Multivariate Analysis of Variance (MANOVA) was used to compare factor scores across mission platforms (Table 6). The Wilks' Lambda (Tatsuoka, 1971) was used and a simple main effect was found between platform and personality domain, [Wilk's $\Lambda=.684, F(15,185.359)=1.824, p=.034$ ]. The multivariate $\eta^{2}=.119$, is weak, and indicates only about $12 \%$ of the multivariate variance of the personality domains are associated with the platform factor.

Post hoc analyses were conducted using the Analysis of Variances (ANOVA) on each dependent variable as follow-up procedures to the significant MANOVA outcome (Table 7). Using the Bonferroni method (correcting the alpha level to guard against Type I errors), each ANOVA was tested at the .01 level. Only Agreeableness was found to be significantly different among aviators across the four mission platforms $[F(3,71)=6.517, p=.001]$.

\section{Table 6}

Multivariate Analysis of Platform and Personality Domains

\begin{tabular}{rcccccc}
\hline Effect & $\begin{array}{c}\text { Wilk's } \\
\text { Lambda }\end{array}$ & $F$ & $\begin{array}{c}\text { Hypothesis } \\
d f\end{array}$ & $\begin{array}{c}\text { Error } \\
d f\end{array}$ & Sig. & $\begin{array}{c}\text { Partial Eta } \\
\text { Squared }\end{array}$ \\
\hline Platform & .684 & 1.82 & 15.00 & 185.359 & .034 & .119 \\
\hline
\end{tabular}


Table 7

Analysis of Variance for the Five-Factor Model Factors

\begin{tabular}{|c|c|c|c|c|c|c|c|}
\hline Factor & & $\begin{array}{l}\text { Sum of } \\
\text { Squares }\end{array}$ & $d f$ & $\begin{array}{l}\text { Mean } \\
\text { Square }\end{array}$ & $F$ & Sig. & $\begin{array}{c}\text { Partial } \\
\text { Eta } \\
\text { Squared }\end{array}$ \\
\hline Neuroticism & $\begin{array}{l}\text { Contrast } \\
\text { Error }\end{array}$ & $\begin{array}{r}1124.569 \\
24316.577\end{array}$ & $\begin{array}{r}3 \\
71\end{array}$ & $\begin{array}{l}374.856 \\
342.487\end{array}$ & 1.095 & .357 & .044 \\
\hline Extraversion & $\begin{array}{l}\text { Contrast } \\
\text { Error }\end{array}$ & $\begin{array}{r}230.078 \\
25344.509\end{array}$ & $\begin{array}{r}3 \\
71\end{array}$ & $\begin{array}{r}76.693 \\
356.965\end{array}$ & .215 & .886 & .009 \\
\hline Openness & $\begin{array}{l}\text { Contrast } \\
\text { Error }\end{array}$ & $\begin{array}{r}322.485 \\
22152.182\end{array}$ & $\begin{array}{r}3 \\
71\end{array}$ & $\begin{array}{l}107.495 \\
312.003\end{array}$ & .345 & .793 & .014 \\
\hline Agreeableness & $\begin{array}{l}\text { Contrast } \\
\text { Error }\end{array}$ & $\begin{array}{r}4219.682 \\
15325.065\end{array}$ & $\begin{array}{r}3 \\
71\end{array}$ & $\begin{array}{r}1406.561 \\
215.846\end{array}$ & 6.517 & .001 & .216 \\
\hline Conscientiousness & $\begin{array}{l}\text { Contrast } \\
\text { Error }\end{array}$ & $\begin{array}{r}1227.432 \\
22988.915 \\
\end{array}$ & $\begin{array}{r}3 \\
71 \\
\end{array}$ & $\begin{array}{l}409.144 \\
323.788 \\
\end{array}$ & 1.264 & .293 & .051 \\
\hline
\end{tabular}

Given the statistically significant difference among aviators on the Agreeableness factor show in Table 7, and the fact that Attack pilots scored lower on the Agreeableness factor than those from the other three platforms $(M=103.81$ from Table 4), a follow-up analysis of the Agreeableness facet scores was conducted using an exploratory MANOVA. The findings revealed a significant interaction between aviator platform and the scores on the Agreeableness facets [Wilk's $\Lambda=.619, F(18,187.161)=1.923, p=.016]$. Post hoc analyses of this significant interaction consisted of pairwise comparisons using the ANOVA with Bonferroni correction to determine differences among the mission platforms for the Agreeableness factor. That is, a series of 12 pairwise comparisons were performed, comparing the four platforms with each other with respect to their scores on the Agreeableness factor. The results of these tests are presented in Table 8. 
Table 8

Pairwise Comparisons Among Mission Platforms

\begin{tabular}{|c|c|c|c|c|c|}
\hline Factor & $\begin{array}{l}\text { (I) Mission } \\
\text { Platform }\end{array}$ & $\begin{array}{c}\text { (J) Mission } \\
\text { Platform }\end{array}$ & $\begin{array}{c}\text { Mean } \\
\text { Difference } \\
(\mathrm{I}-\mathrm{J})\end{array}$ & $\begin{array}{l}\text { Std. } \\
\text { Error }\end{array}$ & Sig. \\
\hline \multirow[t]{12}{*}{$\mathrm{AG}$} & \multirow[t]{3}{*}{$\mathrm{A}(M=103.81)$} & $\mathrm{S} / \mathrm{O}(M=114.46)$ & -10.642 & 5.754 & .069 \\
\hline & & $\mathrm{C}(M=113.50)$ & -9.938 & 6.392 & .123 \\
\hline & & $\mathrm{U}(M=122.70)$ & -18.888 & 4.346 & .000 \\
\hline & \multirow[t]{3}{*}{$\mathrm{S} / \mathrm{O}(M=114.46)$} & $\mathrm{A}(M=103.81)$ & 10.642 & 5.754 & .069 \\
\hline & & $\mathrm{C}(M=113.50)$ & .705 & 6.827 & .918 \\
\hline & & $\mathrm{U}(M=122.70)$ & -8.245 & 5.002 & .104 \\
\hline & \multirow[t]{3}{*}{$\mathrm{C}(M=113.50)$} & $\mathrm{A}(M=103.81)$ & 9.938 & 6.392 & .123 \\
\hline & & $\mathrm{S} / \mathrm{O}(M=114.46)$ & -.705 & 6.827 & .918 \\
\hline & & $\mathrm{U}(M=122.70)$ & -8.950 & 5.690 & .120 \\
\hline & \multirow[t]{3}{*}{$\mathrm{U}(M=122.70)$} & $\mathrm{A}(M=103.81)$ & 18.888 & 4.346 & .000 \\
\hline & & $\mathrm{S} / \mathrm{O}(M=114.46)$ & 8.245 & 5.002 & .104 \\
\hline & & $\mathrm{C}(M=113.50)$ & 8.950 & 5.690 & .120 \\
\hline
\end{tabular}

Note. Mission Platform names: $\mathrm{A}=$ Attack; $\mathrm{S} / \mathrm{O}=$ Scout/Observation; $\mathrm{C}=\mathrm{Cargo} ; \mathrm{U}=\mathrm{Utility}$. Factor Name: $\mathrm{AG}=$ Agreeableness.

Under the factor of Agreeableness, the Attack pilots were significantly different from the Utility pilots $(p<.001)$, but not significantly different from Scout/Observation or Cargo aviators at the factor level. The source of difference in Agreeableness was identified to be on the facet of Trust, with Trust scoring significantly $(p<.001)$ different between Attack and Utility aviators (Table 9). Attack aviators were found to score lowest among the four mission platforms on this facet, as shown in Table 9. 
Table 9

Pairwise Comparisons of Trust Among Mission Platforms

\begin{tabular}{clcrr}
\hline $\begin{array}{c}\text { (I) Mission } \\
\text { Platform }\end{array}$ & \multicolumn{1}{c}{$\begin{array}{c}\text { Mean } \\
\text { Platform }\end{array}$} & $\begin{array}{c}\text { Difference } \\
(\mathrm{I}-\mathrm{J})\end{array}$ & Std. Error & \multicolumn{1}{c}{ Sig. } \\
\hline \multirow{2}{*}{$\mathrm{A}(M=17.75)$} & $\mathrm{S} / \mathrm{O}(M=19.36)$ & & & \\
& $\mathrm{C}(M=21.50)$ & -1.6136 & 1.57875 & 1.000 \\
& $\mathrm{U}(M=22.50)$ & -3.7500 & 1.74538 & .210 \\
& $\mathrm{~A}(M=17.75)$ & -4.7500 & 1.19232 & .001 \\
\hline $\mathrm{S} / \mathrm{O}(M=19.36)$ & $\mathrm{C}(M=21.50)$ & 1.6136 & 1.57875 & 1.000 \\
& $\mathrm{U}(M=22.50)$ & -2.1364 & 1.87294 & 1.000 \\
& $\mathrm{~A}(M=17.75)$ & -3.1364 & 1.37229 & .152 \\
\hline $\mathrm{C}(M=21.50)$ & $\mathrm{S} / \mathrm{O}(M=19.36)$ & 3.7500 & 1.74538 & .210 \\
& $\mathrm{U}(M=22.50)$ & 2.1364 & 1.87294 & 1.000 \\
& $\mathrm{~A}(M=17.75)$ & -1.0000 & 1.56111 & 1.000 \\
\hline $\mathrm{U}(M=22.50)$ & $\mathrm{S} / \mathrm{O}(M=19.36)$ & 4.7500 & 1.19232 & .001 \\
& $\mathrm{C}(M=21.50)$ & 3.1364 & 1.37229 & .152 \\
& & 1.0000 & 1.56111 & 1.000 \\
\hline
\end{tabular}

Note. Mission Platform names: $\mathrm{A}=$ Attack; $\mathrm{S} / \mathrm{O}=$ Scout/Observation; $\mathrm{C}=\mathrm{Cargo} ; \mathrm{U}=\mathrm{Utility}$

\section{Discussion}

Personality has been a research focus as a possible predictor of performance and other workplace outcomes such as job satisfaction and tenure. The NEO-PI-R is a valid personality instrument that has been successful in predicting performance with aviators. Two research questions guided this investigation.

First, findings from the current investigation resulted in a personality profile for the total sample as well as for aviators across the four specific mission platforms. The total sample profile was low on Neuroticism and Openness and average on the remaining three factors. Since Conscientiousness was only two raw score points from the high range, a larger sample might produce different results. Based on these scores this sample of U.S. Army rotary-wing aviators was not unlike the average person in the general public in terms of personality. Army aviators might be more emotionally stable and calm under pressure and they might be more committed to following standard operating procedures rather than engaging in maverick behaviors.

Second, the only significant difference between the aviators based upon their primary mission platform was on Agreeableness. The Agreeableness facet of Trust was significantly different between Attack and Utility aviators. Attack aviators scored lower than Utility aviators on this facet. Agreeableness involves sociability, cooperation, and other dimensions of teamwork. Low Agreeableness on the part of Attack aviators suggests that those sampled might place more emphasis on aspects of cockpit performance other than interpersonal relationships. 
While caution should be exercised in interpreting what this difference on the Agreeableness factor might mean, it is consistent with the descriptions provided in interviews with two instructor pilots. Their anecdotal description of Attack aviators was that they are more committed to mission success and cockpit performance than they are to developing interpersonal relationships in the cockpit. Utility aviators were described as being friendly and cooperative and ready to do whatever they are called upon to do. Anecdotal descriptions aside, it might be that this difference is related to the finding of Chidester et al. (1991) that aviators respond differently to training, especially when the training concerns developing interpersonal skills.

The findings of this investigation were not consistent with research results suggesting that military aviators exhibit personality trait levels that distinguish them from the general public (Callister, et al., 1997; 1999; Fitzgibbons, et al., 2004; Helton \& Street, 1993; Street \& Helton, 1993). The aviators in this sample scored low to average across the five factors, and the low scores were near the average range. This indicates that this sample of aviators was similar to the personality trait levels of the general public.

The overall low Neuroticism and Openness scores would seem to suggest that these aviators are able to mitigate stress in the cockpit and prefer to comply with procedures rather than engage in efforts to create novel approaches to cockpit decision-making. The average Extraversion and Agreeableness scores indicate that this sample is moderately social and active, but the respondents value their privacy and are generally warm and cooperative. Average Conscientiousness indicates these aviators are dependable and moderately goal-oriented. In other words, the romantic stereotype of military pilots as being extraverted, risk-taking, mavericks, with little interest in procedural compliance, was not supported by these findings.

The only other reported study to consider the possibility of personality traits clustering differently among U.S. Army rotary-wing aviators (Picano, 1991) found three personality clusters that seemed to correspond to the Retzlaff and Gibertini (1987) classification of the "wrong stuff," "company man," and "right stuff." Picano's "methodical extroverts" were outgoing and used a structured problem-solving approach emphasizing planning, logical analysis, and attention to detail. They were also concerned with maintaining a positive image as an aviator that would reflect positively on the Army. The "introverted worriers" were emotionally controlled, inhibited, and appeared apprehensive. They tended to prefer stability and predictability, and were uncomfortable in social situations. The "competitive individualists" were described as highly independent, competitive, and decisive. They were the least emotionally sensitive and exhibited the lowest concern for making a good impression. Picano's study did not reveal marked differences in personality across mission platforms, but he recommended further personality research with Army aviators.

The inter-platform findings of this study may suggest that Attack Army aviators are more similar to Picano's (1991) description of "competitive individualists." They were found to be significantly less concerned with maintaining agreeable relationships and more concerned with performancc. The Utility aviators, with higher Agreeableness scores than Attack aviators, may be most similar to Picano's depiction of "methodical extroverts." How the Army's Scout and Cargo aviators would fit with Picano's conceptualization is unclear. A larger sample size might 
help to clarify these possible relationships and would thus extend the findings of Picano as well as Retzlaff and Gibertini (1987) to the US Army rotary-wing aviator of today.

\section{Conclusions}

This investigation was an initial step in increasing what is known about the personality traits of U.S. Army rotary-wing aviators. This investigation was successful in identifying a personality profile based upon the FFM, and identified one factor (Agreeableness) upon which they differed when grouped by mission platform. One of the limitations of this investigation was the sample size. While the total sample was 75 aviators, the dispersion when the aviators were grouped by mission platform was large, ranging from 40 Utility to 8 Cargo pilots.

\section{Future Research}

Many questions remain and warrant future research. Would a larger sample change the profiles overall or across mission platforms that were reported in this investigation? How does personality influence performance in initial flight training? Should an instrument such as the NEO-PI-R be used in classification decisions?

Aviation research has supported the notion that personality trait levels can predict cockpit performance (e.g., mission success, teamwork, risk-taking), especially during flight training (Anesgart \& Callister, 2001). Therefore, NEO-PI-R scores were collected for a sample of 240 incoming Army flight students, and data reflecting their flight school performance were subsequently collected. That investigation and its findings will be documented in a future ARI report.

Efforts are currently underway to develop an instrument for the classification of Army aviators into the four main mission types during initial flight training. One component of this program will be the administration of the NEO-PI-R to experienced Army aviators. This will effectively enlarge the sample size and enhance the findings of this investigation, potentially clarifying personality differences across mission platforms. 
References

American Heritage Dictionary ( $3^{\text {rd }}$ ed.). (1994). Boston, MA: Houghton Mifflin Company.

Anesgart, M. N., \& Callister, J. D. (2001). Predicting training success with the NEO-PI-R: The use of logistic regression to determine the odds of completing a pilot screening program (AFRL-HE-WP-TR-2001-0074). Wright-Patterson AFB, OH: United States Air Force Research Laboratory Human Effectiveness Directorate.

Ashman, A., \& Tefler, R. (1983). Personality profiles of pilots. Aviation Space and Environmental Medicine, 54, 940-943.

Assouline, M., \& Meir, E. I. (1987). Meta-analysis of the relationship between congruence and well-being measures. Journal of Vocational Behavior, 31, 319-332.

Avdeyeva, T. V., \& Church, A. T. (2005). The cross-cultural generalizability of personality types: A Philippine study. European Journal of Personality, 19, 475-499.

Barrick, M. R., \& Mount, M. K. (1991). The big five personality dimensions and job performance: A meta-analysis. Personnel Psychology, 44, 1-26.

Barrick, M. R., \& Mount, M. K. (1993). Autonomy as a moderator of the relationships between the Big Five personality dimensions and job performance. Journal of Applied Psychology, 78(1), 111-118.

Barrick, M. R., \& Mount, M. K. (1996). Effects on impression management and self-deception on the predictive validity of personality constructs. Journal of Applied Psychology, 81(3), 261-272.

Barrick, M. R., Mount, M. K., \& Gupta, R. (2003). Meta-analysis of the relationship between the five-factor model of personality and Holland's occupational types. Personnel Psychology, 56, 45-74.

Barrick, M. R., Mount, M. K., \& Judge, T. A. (2001). Personality and performance at the beginning of the new millennium: What do we know and where do we go next? Personality and Performance, 9(1/2), 9-30.

Barry, B., \& Stewart, G. L. (1997). Composition, process, and performance in self-managed groups: The role of personality. Journal of Applied Psychology, 82, 62-78.

Bartram, D. (1995). The predictive validity of the EPI and 16PF for military flying training. Journal of Occupational and Organizational Psychology, 68, 219-236.

Ben-Porath, Y. S., \& Waller, M. K. (1992). Five big issues in clinical personality assessment: A rejoinder to Costa and McCrae. Psychological Assessment, 4, 23-25. 
Bernard, L. C., \& Walsh, P. (2004). Socially desirable and non-purposeful responding on the Neuroticism Extraversion Openness Personality Inventory-Revised. Counseling and Clinical Psychology Journal, 1(1), 4-16.

Bucky, S. F., \& Ridley, S. L. (1972). California Psychological Inventory as a predictor of success in the Naval flight program. Aerospace Medicine, 43, 971-973.

Butcher, J. N., Dahlstrom, W. G., Graham, J. R., Tellegen, A., \& Kaemmer, B. (1989). MMPI-2: Manual for administering and scoring. Minneapolis: University of Minnesota Press.

Butcher, J. N., \& Rouse, S. V. (1996). Personality: Individual differences and clinical assessment. Annual Review of Psychology, 47, 87-111.

Caldwell, J. A., Jr., O'Hara, C., Caldwell, J. L., Stephens, R. L., \& Krueger, G. P. (1993). Personality profiles of U.S. Army helicopter pilots screened for special operations duty. Military Psychology, 5(3), 187-209.

Callister, J. D., King, R. E., Retzlaff, P. D., \& Marsh, R. W. (1997). Using the NEO-PI-R to assess the personality of U.S. Air Force pilots (AL/AO-TR-1997-0097). Brooks Air Force Base, TX: Aerospace Medicine Directorate, Clinical Sciences Division, Neuropsychiatry Branch.

Callister, J. D., King, R. E., Retzlaff, P. D., \& Marsh, R. W. (1999). Revised NEO personality inventory profiles of male and female U.S. Air Force pilots. Military Medicine, 164, 885-890.

Caprara, G. V., Barbaranelli, C., Borgogni, L., \& Perugini, M. (1993). The 'Big-Five Questionnaire': A new questionnaire to assess the Five Factor Model. Personality and Individual Differences, 15, 281-288.

Caspi, A., Roberts, B. W., Shiner, R. (2005). Personality development. Annual Review of Psychology, 56, 453-484.

Chidester, T., Helmreich, R., Gregorich, S., \& Geis, C. (1991). Pilot personality and crew coordination: Implications for training and selection. The International Journal of Aviation Psychology, 1, 25-44.

Colucci, F. (2002). Army to outsource rotary-wing pilot training: Flight School XXI is expected to improve overall aviation skills and combat readiness. National Defense Magazine. Retrieved 6/5/05 from www.nationaldefensemagazine.org/issues/2002/Nov/Army to Outsource.htm.

Costa, P. T., Jr., Busch, C. M., Zonderman, A. B., \& McCrae, R. R. (1986). Correlations of the MMPI factor scales with measures of the five factor model of personality. Journal of Personality Assessment, 50, 640-650. 
Costa, P. T., Jr., \& McCrae, R. R. (1985). The NEO Personality Inventory manual. Odessa, FL: Psychological Assessment Resources.

Costa, P. T., Jr., \& McCrae, R. R. (1992). Professional manual Revised NEO Personality Inventory (NEO-PI-R) and NEO Five-Factor Inventory (NEO-FFI). Odessa, FL: Psychological Assessment Resources, Inc.

Costa, P. T., Jr., \& McCrae, R. R. (1997). Stability and change in personality assessment: The revised NEO Personality Inventory in the year 2000. Journal of Personality Assessment, 68(1), 86-94.

Costa, P. T., Jr., McCrae, R. R., \& Dye, D. A. (1991). Facet scales for Agreeableness and Conscientiousness: A revision of the NEO Personality Inventory. Personality and Individual Differences, 12, 887-898.

Costa, P. T., Jr., McCrae, R. R., \& Kay, G. G. (1995). Persons, places, and personality: Career assessment using the Revised NEO Personality Inventory. Journal of Career Assessment, 3, 123-139.

Culpepper, B., Jennings, C., \& Perry, C. (1972). Psychiatric and psychometric predictability of test pilot school performance. Aerospace Medicine, 43, 1257-1260.

Davis, R. A. (1989). Personality: Its use in selecting candidates for US Air force undergraduate pilot training (AU-ARI-88-8). Maxwell Air Force Base, TX: Air University.

De Fruyt, F., \& Mervielde, I. (1999). RIASEC types and big five traits as predictors of employment status and nature of employment. Personnel Psychology, 52, 701-727.

Digman, J. M. (1989). Five robust trait dimensions: Development, stability, and utility. Journal of Personality, 57, 195-214.

Digman, J. M. (1990). Personality structure: Emergence of the five-factor model. Annual Review of Psychology, 41, 417-440.

Dockery, F. C., \& Isaacs, S. (1921). Psychological research in aviation in Italy, France, England, and the American Expeditionary Forces. Journal of Comparative Psychology, 1, 115148.

Dolgin, D. L., \& Gibb, G. D. (1988). A review of personality measurement in aircrew selection (NAMRL Monograph 36). Pensacola, FL: Naval Aerospace Medical Research Laboratory.

Dolgin, D. L., Kay, G. G., Langelier, M. K., Wasel, B. D., \& Hoffman, C. (2002). Identification of the cognitive, psychomotor, and psychosocial skill demands of uninhabited combat air vehicle (UCAV) operators. Space and Flight Equipment Journal, 30, 219-225. 
Driskell, J. E., Hogan, R., \& Salas, E. (1987). Personality and group performance. In C. Hendrick (Ed.), Group processes and intergroup relations (pp. 91-112). Newbury Park, CA: Sage.

Edwards, A. L. (1959). Manual for the Edwards Personal Preference Schedule. Ohio: The Psychological Corporation.

Edwards, J. R. (1996). An examination of competing versions of the person-environment fit approach to stress. Academy of Management Journal, 39, 292-339.

Ellingson, J. E., Smith, D. B., \& Sackett, P. R. (2001). Investigating the influence of social desirability on personality factor structure. Journal of Applied Psychology, 86, 122-133.

Eysenck, H. J. (1970). The structure of human personality ( $3^{\text {rd }}$ ed.). London: Methuen.

Fiske, D. W. (1949). Consistency of the factorial structures of personality ratings from different sources. Journal of Abnormal and Social Psychology, 44, 329-344.

Fitzgibbons, A., Davis, D., \& Schutte, P. C. (2004). Pilot personality profile using the NEO-PIR (NASA/TM-2004-213237). Hampton, VA: National Aeronautics and Space Administration Langley Research Center.

Furnham, A. (2001). Self-estimates of intelligence: Culture and gender differences in self and other estimates of both general (g) and multiple intelligences. Personality and Individual Differences, $31,1381-1405$.

Furnham, A., Moutafi, J., \& Crump, J. (2003). The relationship between the Revised NEOPersonality Inventory and the Myers-Briggs Type Indicator. Social Behavior and Personality, 31(6), 577-584.

Geist, C. R., \& Boyd, S. T. (1980). Personality characteristics of Army helicopter pilots. Perceptual \& Motor Skills, 51, 253-254.

Ghiselli, E. E. (1973). The validity of aptitude tests in personnel selection. Personnel Psychology, 26, 461-477.

Goldberg, L. R. (1981). Language and individual differences: The search for universals in personality lexicons. In L. Wheeler (Ed.), Review of Personality and Social Psychology (pp. 141-165). Beverly Hills, CA: Sage.

Goldberg, L. R. (1990). An alternative "description of personality": The Big-Five factor structure. Journal of Personality and Social Psychology, 59, 1216-1229.

Gregorich, S., Helmreich, R. L., Wilhelm, J. A., \& Chidester, T. (1989). Personality based clusters as predictors of aviator attitudes and performance. In R. S. Jensen (Ed.), 
Proceedings of the $5^{\text {th }}$ International Symposium on Aviation Psychology (Vol. II; pp. 686691). Columbus, OH: Ohio State University.

Guion, R. M., \& Gottier, R. F. (1965). Validity of personality measures in personnel selection. Personnel Psychology, 18, 135-164.

Hathaway, S. R., \& McKinley, J. C. (1943). Manual for administering and scoring the MMPI. Minneapolis: University of Minnesota Press.

Helmreich, R. L., Sawin, L. L., Carsrud, A. L. (1986). The Honeymoon Effect in job performance: Temporal increases in the predictive power of achievement motivation. The Journal of Applied Psychology, 71(2), 185-188.

Helmreich, R. L., \& Wilhelm, J. (1989). Validating personality constructs for flightcrew selection: Status report on the NASA/UT project (NASA/TU Technical Memorandum, 89-3). Austin, TX: University of Texas.

Helton, K. T., \& Street, D. R., Jr. (1993). The five-factor personality model and naval aviation candidates (NAMRL-1379). Pensacola, FL: Naval Aerospace Medical Research Laboratory.

Hilton, T. R., \& Dolgin, D. L. (1991). Pilot selection in the military of the free world. In R. Gal and A. D. Mangelsdorff (Eds.), Handbook of Military Psychology (pp. 88-101). Sussex, England: John Wiley and Sons.

Hogan, R. (2005). In defense of personality measurement: New wine for old whiners. Human Performance, 18(4), 331-341.

Holden, R. R., \& Hibbs, R. (1995). Incremental validity of response latencies for detecting fakers on a personality test. Journal of Research in Personality, 29(3), 362-372.

Holland, J. L. (1973). Making vocational choices: A theory of career. Englewood Cliff, NJ: Prentice Hall.

Holland, J. L. (1978). Manual for the vocational preferences inventory. Palo Alto, CA: Consulting Psychologist Press.

Holland, J. L. (1985a). Manual for the self-directed search. Odessa, FL: Psychological Assessment Resources.

Holland, J. L. (1985b). Professional manual: Vocational Preference Inventory, 1985 edition. Odessa, FL: Psychological Assessment Resources.

Holland, D. C., Dollinger, S. J., Holland, C. J., \& MacDonald, D. A. (1995). The relationship between psychometric intelligence and the five-factor model of personality in a rehabilitation sample. Journal of Clinical Psychology, 51(1), 79-88. 
Hormann, H., \& Maschke, P. (1996). On the relation between personality and job performance of airline pilots. The International Journal of Aviation Psychology, 6(2), 171-178.

Hough, L. M., Eaton, N. K., Dunnette, M. D., Kamp, J. D., \& McCloy, R. A. (1991). Criterionrelated validities of personality constructs and the effects of response distortion on those validities. Journal of Applied Psychology, 75, 581-595.

Intano, G. P., Howse, W. R., \& Lofaro, R. J. (1991). The selection of an experimental test battery for aviator cognitive, psychomotor abilities and personal traits (USARI Research Note 91-21). Alexandria, VA: U.S. Army Research Institute for the Behavioral and Social Sciences.

Jang, K. L., McCrae, R. R., Angleitner, A., Riemann, R., \& Livesley, W. J. (1998). Heritability of facet-level traits in a cross-cultural twin sample: Support for a hierarchical model of personality. Journal of Personality and Social Psychology, 74, 1556-1565.

Jessup, G., \& Jessup, H. (1971). Validity of the Eysenck Personality Inventory in pilot selection. Occupational Psychology, 45, 111-123.

John, O. P., Goldberg, L. R., \& Angleitner, A. (1984). Better than the alphabet: Taxonomies of personality-descriptive terms in English, Dutch, and German. In H. Bonarius, G. Van Heck, \& N. Smid (Eds.), Personality psychology in Europe: Theoretical and empirical developments (pp. 83-100). Lisse, Netherlands: Swets \& Zeitlinger.

John, O. P., \& Srivastava, S. (1999). The Big Five trait taxonomy: History, measurement, and theoretical perspectives. In L. A. Pervin \& O. P. John (Eds.), Handbook of personality: Theory and research, $2^{\text {nd }}$ ed. (pp 102-138). New York: Guilford Press.

Judge, T. A., \& Cable, D. M. (1997). Applicant personality, organizational culture, and organization attraction. Personnel Psychology, 50(2), 359-394.

Judge, T. A., Heller, D., \& Mount, M. K. (2002). Five-Factor model of personality and job satisfaction: A meta-analysis. Journal of Applied Psychology, 87, 530-541.

Judge, T. A., \& Ilies, R. (2002). Relationship of personality to performance motivation: A meta-analytic review. Journal of Applied Psychology, 87(4), 797-807.

Kanki, B. G., \& Palmer, M. T. (1993). Communication and crew resource management. In E. L. Wiener, B. G. Kanki, \& R. L. Helmreich (Eds.), Cockpit resource management (pp. 99-136). San Diego, CA: Academic Press.

Kanki, B. G., Palmer, M. T., \& Veinott, E. (1991). Communication variations related to leader personality. In Proceedings of the Sixth International Symposium on Aviation Psychology (pp. 253-259). Columbus, $\mathrm{OH}$ : Ohio State University. 
Kieffer, K. M., Schnika, J. A., \& Curtiss, G. (2004). Person-environment congruence and personality domains in the prediction of job performance and work quality. Journal of Counseling Psychology, 51(2), 168-177.

King, R. E. (1994). Assessing aviators for personality pathology with the Millon Clinical Multiaxial Inventory (MCMI). Aviation, Space, and Environmental Medicine, 65(3), 227-231.

King, R. E., \& Flynn, C. F. (1995). Defining and measuring the "Right Stuff": Neuropsychiatrically enhanced flight screening (N-EFS). Aviation, Space, and Environmental Medicine, 66, 951-956.

King, R. E., McGlohn, S. E., \& Retzlaff, P. D. (1997). Female United States Air Force pilot personality: The new right stuff. Military Medicine, 162, 695-697.

King, R. E., Retzlaff, P. D., Detwiler, C. A., Schroeder, D. J., \& Broach, D. (2003). Use of personality assessment measures in the selection of air traffic control specialists (DOT/FAA/AM-03/20 Technical Report). Washington, DC: Office of Aerospace Medicine.

Klein, H. J., \& Lee, S. (2006). The effects of personality on learning: The mediating role of goal setting. Human Performance, 19(1), 43-66.

Kurtz, J. E., Lee, P. A., \& Sherker, J. L. (1999). Internal and temporal reliability estimates for informant ratings of personality using the NEO-PI-R and IAS. Assessment, 6(2), 103113.

Kurtz, J. E., \& Parrish, C. L. (2001). Semantic response consistency and protocol validity in structured personality assessment: The case of the NEO-PI-R. Journal of Personality Assessment, 76(2), 315-332.

Lardent, C. L., Jr. (1991). Pilots who crash: Personality constructs underlying accident prone behavior of fighter pilots. Multivariate Experimental Clinical Research, 10(1), 1-25.

Larson, L. M., Rottinghaus, P. J., \& Borgen, F. H. (2002). Meta-analyses of big six interests and Big Five personality factors. Journal of Vocational Behavior, 61, 217-239.

Latham, G. P., \& Pinder, C. C. (2005). Work motivation theory and research at the dawn of the twenty-first century. Annual Review of Psychology, 56, 485-516.

McCormack, L, \& Mellor, D. (2002). The role of personality in leadership: An application of the Five-Factor Model in the Australian military. Military Psychology, 14(3), 179-197.

McCrae, R. R., \& Allik, J. (2002). The Five-Factor Model of Personality across cultures. New York: Kluwer Academic/Plenum Publishers. 
McCrae, R. R., \& Costa, P. T., Jr. (1990). Personality in adulthood. New York: Guildford.

McCrae, R. R., Costa, P. T., Jr., del Pilar, G., Rolland, J. P., \& Parker, W. D. (1998). Crosscultural assessment of the Five-Factor model: The Revised NEO Personality Inventory. Journal of Cross-Cultural Psychology, 29, 171-188.

McCrae, R. R., Zonderman, A. B., Costa, P. T., Jr., Bond, M. H., \& Paunonen, S. V. (1996). Evaluating replicability of factors in the Revised NEO Personality Inventory: Confirmatory factor analysis versus Procrustes rotation. Journal of Personality and Social Psychology, 70, 552-566.

McGlohn, S. E. (1996). Psychological aspects of aviators' success (USAF Final Report MIPR No. 96MM6644). Brooks Air Force Base, TX: Armstrong Laboratory.

Millon, T. (1977). Millon Clinical Multiaxial Inventory, manual. Minneapolis: National Computer Inventory and Computer Systems.

Mount, M. K., \& Barrick, M. R. (1998). Five reasons why the "Big Five" article has been frequently cited. Personnel Psychology, 51, 849-857.

Mount, M. K., Barrick, M. R., \& Stewart, G. L. (1998). Five-factor model of personality and performance in jobs involving interpersonal interactions. Human Performance, 11(2/3), $145-165$.

Murray, S. R. (1999). FACE: Fear of loss of face and the five hazardous attitudes concept. International Journal of Aviation Psychology, 9(4), 403-411.

Musson, D. M., Sandal, G. M., \& Helmreich, R. L. (2004). Personality characteristics and trait clusters in final stage astronaut selection. Aviation, Space, and Environmental Medicine, 75(4), 342-349.

Myers, I. B., \& McCauley, M. H. (1985). Manual: A guide to the development and use of the Myers-Briggs Type Indicator. Palo Alto, CA: Consulting Psychologists Press.

Norman, W. T. (1963). Toward an adequate taxonomy of personality attributes: Replicated factor structure in peer nomination personality ratings. Journal of Abnormal and Social psychology, 66, 574-583.

O'Reilly, C., Chatman, J., \& Caldwell, D. F. (1991). People and organizational culture: A profile comparison approach to assessing person-organization fit. Academy of Management Journal, 34, 487-516.

Ostroff, C., \& Rothausen, T. J. (1997). The moderating effect of tenure in person-environment fit: A field study in educational organizations. Journal of Occupational and Organizational Psychology, 70, 173-188. 
Paunonen, S. V., \& Ashton, M. C. (2001). Big Five Factors and facets and the prediction of behavior. Journal of Personality and Social Psychology, 81(3), 524-539.

Paunonen, S. V., Jackson, D. D., Trzebinski, J., \& Forsterling, F. (1992). Personality structure across cultures: A multi-method evaluation. Journal of Personality and Social Psychology, 62, 447-456.

Pedersen, L. A., Allan, K. E., Laue, F. J., Johnson, J. R., \& Siem, F. M. (1992). Personality theory for aircrew selection and classification (USAF Technical Report No. AL-TR1992-0021). Brooks Air Force Base, TX: Armstrong Laboratory.

Picano, J. J. (1991). Personality types among experienced military pilots. Aviation, Space, and Environmental Medicine, June, 517-520.

Ployhart, R. E., Lim, B., \& Chan, K. (2001). Exploring relations between typical and maximum performance ratings and the five factor model of personality. Personnel Psychology, 54, 809-843.

Reinhardt, R. F. (1970). The outstanding jet pilot. American Journal of Psychiatry, 127, 732736.

Retzlaff, P. D., \& Gibertini, M. (1987). Air Force pilot personality: Hard data on the right stuff. Multivariate Behavioral Research, 22(4), 383-389.

Rippon, T. S., \& Manuel, E. G. (1918). The essential characteristics of successful and unsuccessful aviators. The Lancet, September, 411-415.

Rosse, J. G., Stecher, M. D., Miller, J. L., \& Levin, R. A. (1998). The impact of response distortion on preemployment personality testing and hiring decisions. Journal of Applied Psychology, 83, 634-644.

Salgado, J. F. (2003). Predicting job performance using FFM and non-FFM personality measures. Journal of Occupational and Organizational Psychology, 76, 323-346.

Scarpello, V. G., Ledvinka, J., \& Bergmann, T. J. (1995). Human resource management. Cincinnati, OH: South-Western College Publishing.

Schinka, J. A., Dye, D. A., \& Curtiss, G. (1997). Correspondence between five-factor and RIASEC models of personality. Journal of Personality Assessment, 68(2), 355-368.

Schinka, J. A., Kinder, B., \& Kremer, T. (1997). Research validity scales for the NEO-PI-R: Development and initial validation. Journal of Personality Assessment, 68, 127-138.

Schmitt, N., Cortina, J. M., Ingerick, M. J., \& Wiechmann, D. (2003). Personnel selection and employee performance. In W. C. Borman, D. R. Ilgin, \& R. J. Klimoski (Eds.), Handbook of Psychology (Vol. 12; pp. 77-106). New York: Wiley. 
Schmitt, N., Gooding, R. Z., Noe, R. A., \& Kirsch, M. (1984). Meta-analysis of validity studies published between 1964 and 1982 and the investigation of study characteristics.

Personnel Psychology, 37, 407-422.

Schneider, B. (1983). Interactional psychology and organizational behavior. In I. I. Cummings \& B. M. Staw (Eds.), Research in Organizational Behavior, (Vol. 5). Greenwich, CT: JAI Press.

Schneider, B. (1987). The people make the place. Personnel Psychology, 40, 437-453.

Seibert, S. E., \& Kraimer, M. L. (2001). The five-factor model of personality and career success. Journal of Vocational Behavior, 58(1), 1-21.

Shinar, Y. (1995). Personality as the key factor in the competence of a pilot. In R.S. Jensen (Ed.), Proceedings of the Eighth International Symposium on Aviation Psychology (pp. 1137-1141). Columbus, $\mathrm{OH}$ : The Ohio State University.

Siem, F. M., \& Murray, M. W. (1994). Personality factors effecting pilot combat performance: A preliminary investigation. Aviation, Space, \& Environmental Medicine, 65(5, Sect 2, Suppl), A45-A48.

Street, D., \& Helton, K. (1993). The 'right stuff': Personality tests and the five factor model in landing craft air cushion crew training. Proceedings of the Human Factors and Ergonomics Society $37^{\text {th }}$ annual meeting. (920-924).

Street, D. R., Jr., Helton, K. T., \& Nontasak, T. (1994). An evaluation of personality testing and the five-factor model in the selection of landing craft air cushion vehicle crew members (NAMRL-1385). Pensacola, FL: Naval Aerospace Medical Research Laboratory.

Sullivan, B. A., \& Hansen, J. C. (2004). Mapping associations between interests and personality: Toward a conceptual understanding of individual differences in vocational behavior. Journal of Counseling Psychology, 51(3), 287-298.

Tabachnick, B. G., \& Fidell, L. S. (2001). Using multivariate statistics (4 ${ }^{\text {th }}$ ed.). Boston: Allyn and Bacon.

Tatsuoka, M. M. (1971). Multivariate analysis: Techniques for educational and psychological research. New York: Wiley.

Tett, R. P., \& Burnett, D. D. (2003). A personality trait-based interactionist model of job performance. Journal of Applied Psychology, 88(3), 500-517.

Trull, T. J., \& Geary, D. C. (1997). Comparison of the Big-Five Factor structure across samples of Chinese and American adults. Journal of Personality Assessment, 69(2), 324-341. 
Tsaousis, I., \& Nikolaou, I. E. (2001). The stability of the Five-Factor Model of personality in personnel selection and assessment in Greece. International Journal of Selection and Assessment, 9(4), 290-301.

Tupes, E. C. (1957). Personality traits related to effectiveness of junior and senior Air Force officers (USAF Personnel Training Research, No. 57-125). Lackland Air Force Base, TX: Aeronautical Systems Division, Personnel Laboratory.

Tupes, E. C., \& Christal, R. E. (1961). Recurrent personality factors based on trait ratings (USAF ASD Tech Report No. 61-97). Lackland Air Force Base, TX: Aeronautical Systems Division, Personnel Laboratory.

Ursano, R. J. (1980). Stress and adaptation: The interaction of the pilot personality and disease. Aviation, Space, and Environmental Medicine, 51, 1245-1249.

Vickers, R. R., Jr. (1995). Using personality assessment for leadership selection (NHRC Report No. 95-16). San Diego, CA: Naval Health Research Center.

Waldman, D. A., Atwater, L. E., \& Davidson, R. A. (2004). The role of individualism and the five-factor model in the prediction of performance in a leaderless group discussion. Journal of Personality, 72(1), 1-25.

Wechsler D. (1981). Wechsler adult intelligence scale-revised. New York: Psychological Corporation. 